\title{
Stimulus onset asynchrony and the timeline of word recognition: Event-related potentials during sentence reading
}

\author{
Michael Dambacher ${ }^{\mathrm{a}, \mathrm{b}, *}$, Olaf Dimigen ${ }^{\mathrm{b}, \mathrm{c}}$, Mario Braun $^{\mathrm{a}, \mathrm{d}}$, Kristin Wille ${ }^{\mathrm{b}}$, \\ Arthur M. Jacobs ${ }^{\mathrm{a}, \mathrm{d}}$, Reinhold Kliegl ${ }^{\mathrm{b}}$ \\ a Department of Education and Psychology, Freie Universität Berlin, Habelschwerdter Allee 45, 14195 Berlin, Germany \\ ${ }^{b}$ Department of Psychology, Universität Potsdam, Karl-Liebknecht Str. 24-25, 14476 Potsdam, Germany

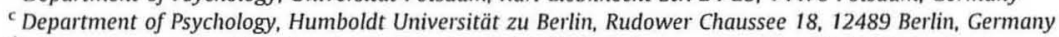 \\ ${ }^{\mathrm{d}}$ Dahlem Institute for Neuroimaging of Emotion (D.I.N.E.). Habelschwerdter Allee 45, 14195 Berlin, Germany
}

Keywords:

Word recognition

Sentence reading

Stimulus onset asynchrony (SOA)

Frequency

Predictability

Event-related potentials (ERPs)

\begin{abstract}
A B S T R A C T
Three ERP experiments examined the effect of word presentation rate (i.e., stimulus onset asynchrony, SOA) on the time course of word frequency and predictability effects in sentence reading. In Experiments 1 and 2 , sentences were presented word-by-word in the screen center at an SOA of 700 and $490 \mathrm{~ms}$, respectively. While these rates are typical for psycholinguistic ERP research, natural reading happens at a considerably faster pace. Accordingly, Experiment 3 employed a near-normal SOA of $280 \mathrm{~ms}$, which approximated the rate of normal reading. Main results can be summarized as follows: (1) The onset latency of early frequency effects decreases gradually with increasing presentation rates. (2) An early interaction between top-down and bottom-up processing is observed only under a near-normal SOA. (3) N400 predictability effects occur later and are smaller at a near-normal (i.e., high) presentation rate than at the lower rates commonly used in ERP experiments. (4) ERP morphology is different at the shortest compared to longer SOAs. Together, the results point to a special role of a near-normal presentation rate for visual word recognition and therefore suggest that SOA should be taken into account in research of natural reading.
\end{abstract}

\section{Introduction}

Arguably, one of the most basic questions of psycholinguistic research is how long it takes to identify a word. Generally, it is assumed that at this moment of lexical access, the mental representation of a word is retrieved from memory and its meaning becomes available. Despite much progress in psycholinguistic research the time course of word identification is not fully understood, even with respect to two major determinants, namely word frequency and word predictability from prior context. As a sophisticated technique in this domain, eventrelated potentials (ERPs) disclose brain-electrical processes of word recognition in real time. Yet, research often uses unnaturally long stimulus onset asynchronies (SOAs), i.e., words are presented at low rates. Such artificial settings may well affect language processing, but effects of SOA on the timeline of word recognition have rarely been studied. Here, we address this issue with manipulations of SOA across three ERP reading studies using

"Corresponding author at: Zukunftskolleg and Department of Psychology, Box D29, Universität Konstanz, 78457 Konstanz, Germany. Tel.: +4907531 88 4376; fax: +4907531883017

E-mail address: michael.dambacher@uni-konstanz.de (M. Dambacher). slow, medium, and near-normal (i.e., reading-like) presentation rates. The data point to modulations of the time course of word recognition especially when SOA approximates the duration of reading fixations. Therefore we argue that presentation rate should be taken into account in research on natural reading.

\subsection{The role of presentation rate}

When skilled readers move their eyes across a text, words are fixated for about 200 to $250 \mathrm{~ms}$ on average before saccades of around 20 to $30 \mathrm{~ms}$ bring the next string to the fovea. Eye movements reflect the dynamics of word recognition in natural reading as they mirror the ease or difficulty of language processing. For instance, fixation durations are longer when lexical processing is difficult, as on infrequent or less predictable words. Conversely, frequent and highly predictable words are inspected more briefly or are often not fixated at all (Kliegl, Nuthmann, \& Engbert, 2006; Rayner, 1998, 2009; Rayner, Pollatsek, Ashby, \& Clifton, 2012). Such findings document a rapid influence of word difficulty on oculomotor behavior within a few hundred milliseconds. Nevertheless, the temporal resolution provided by eye movements is limited because they do not disclose information about timelines of lexical processing while words are fixated. 
Timelines of lexical processing can be assessed with ERPs that permit inferences about ongoing neural processes in the range of milliseconds. Thus, unlike measures of reaction times, error rates, or eye movements, brain-electrical responses allow the investigation of word recognition during stimulus processing. However, ERP research faces methodological difficulties that are relevant for the study of reading. First, ERPs are sensitive to ocular artifacts. Because the eyeball acts as a dipole, eye movements and blinks induce changes in scalp voltage that supersede activity related to word processing; eye muscle activity can further distort the EEG signal. Consequently, stimuli are usually presented in a way that renders eye movements unnecessary, that is, one word at a time in the center of the screen (i.e., Rapid Serial Visual Presentation, RSVP). Second, and even more critically, prominent language-related ERP components (e.g., N400 or P600) have long latencies and can last up to one second after stimulus onset. At a natural reading rate of four to five words per second, ERPs to consecutive stimuli would overlap in time such that it becomes difficult to attribute signals to the processing of a unique word (cf., Dambacher \& Kliegl, 2007). This is particularly relevant when properties of pre- and post-target words vary across experimental conditions, as it is often the case in psycholinguistic research. Consequently, words are usually separated by long intervals, resulting in SOAs in the range of around 400 up to $1000 \mathrm{~ms}$.

With low presentation rates we largely circumvent the problem of component overlap, but the timing diverges substantially from the pace of natural sentence reading (cf., Dambacher \& Kliegl, 2007). This divergence in ERP experiments could be problematic if word recognition is optimized for conditions and constraints imposed by eye movements during natural reading and may apply especially to skilled readers, who represent the pool of participants in most psycholinguistic studies. In this case, long SOAs might not disclose "normal" word processing but potentially result in a distorted time course. Yet, little is known about the effect of presentation rate and it is an open question whether findings from long SOAs generalize to natural reading or whether the additional time available for word identification in ERP experiments changes underlying processes or strategies. There are a few studies pointing to good agreement of data assessed under different presentation modes (e.g., Gunter, Jackson, \& Mulder, 1992; see also Van Berkum, 2004), whereas other reports revealed differences in ERPs as a function of input rate (e.g., Camblin Ledoux, Boudewyn, Gordon, \& Swaab, 2007; Hagoort \& Brown, 2000; Hagoort, Brown, \& Groothusen, 1993; Kotz, Von Cramon, \& Friederici, 2005; Ledoux, Gordon, Camblin, \& Swaab, 2007; Swaab, Camblin, \& Gordon, 2004).

For instance, using an SOA of $600 \mathrm{~ms}$ in a sentence reading study, Hagoort et al. (1993) found a Syntactic Positive Shift (SPS or P600/SPS) at around $500 \mathrm{~ms}$ after the onset of a grammatically incorrect word in two of three syntactic violation conditions. In addition, increased N400 amplitudes were observed on the words following the syntactic violation, presumably reflecting increased semantic analysis problems. In a later study using the same sentences and a near-normal SOA of $258 \mathrm{~ms}$, Hagoort and Brown (2000) extended the findings on the P600/SPS as the data showed a positive amplitude shift across all three ungrammatical conditions; notably, onset latencies of the P600/SPS were very similar to those of the long SOA. However, there was no evidence for an N400 modulation on the words following the syntactic violation. Thus, while P600/SPS-related processes seemed comparably robust across reading rates, the $\mathrm{N} 400$ effect critically depended on SOA. The authors proposed that a temporal shift of semantic integration processes at the short compared to the long SOA may have contributed to the absence of the N400 effect.

Ín fact, other studies showed increased N400 latencies for high visual presentation rates (Kutas, 1987; Robichon, Besson, \& Habib,
2002; Rossell, Price, \& Nobre, 2003), but there is also evidence for decreased latencies at natural vs. low rates in speech perception (Holcomb \& Neville, 1991). Considering that the N400 is particularly sensitive to semantic processes (for reviews see Kutas \& Federmeier, 2011; Kutas \& Van Petten, 1994; Kutas, Van Petten, \& Kluender, 2006; see also Lau, Phillips, \& Poeppel, 2008), these findings suggest that context effects in word recognition may well depend on presentation rate.

In order to elude potential confounds of artificial experimental settings, promising progress has been made recently in the development of ERP paradigms that operate under more natural reading situations. This involves, for instance, self-paced reading (e.g., Ditman, Holcomb, \& Kuperberg, 2007) or word-length dependent presentation durations in the RSVP paradigm (e.g., Nieuwland \& Kuperberg, 2008; Nieuwland \& Van Berkum, 2006) as well as the simultaneous recording of EEG and eye movements in normal left-to-right reading (e.g., Dimigen, Sommer, Hohlfeld, Jacobs, \& Kliegl, 2011). Nevertheless, the conditions and extent of effects of presentation rate on the time course of word recognition are not well established.

To investigate effects of SOA, we conducted three experiments, in which the same sentences were displayed at low $(700 \mathrm{~ms})$, medium (490 ms), and near-normal $(280 \mathrm{~ms})$ presentation rates. We examined the time course of language processing by manipulating word frequency and predictability. In the following, we provide a brief overview of previous findings related to these two variables.

\subsection{Word frequency: bottom-up processing and lexical access}

From one perspective, visual perception is driven by bottomup sensory input. Incoming signals travel from the retina to primary visual areas from where they are hierarchically transmitted to higher cortical regions. Ascending this hierarchy, stimulus processing becomes increasingly complex and elaborated until an object is eventually recognized (see Churchland, Ramachandran, \& Sejnowski, 1994, for a discussion). Consistent with this view, word recognition and specifically lexical access has often been regarded as an automatic bottom-up process (Fodor, 1983; Kintsch \& Mross, 1985). That is, the identification of a written word depends on characteristics of the visual input. One of the most dominant item properties influencing processing speed is a word's frequency of occurrence in a language. Reaction times as well as reading fixations point to faster lexical access for high than for low frequency words (Forster \& Chambers, 1973; Inhoff \& Rayner, 1986; Kliegl, Grabner, Rolfs, \& Engbert, 2004; Kliegl et al., 2006; Rayner, 1998; Rubenstein, Garfield, \& Millikan, 1970; Taft, 1979). Consequently, pioneering models of word recognition as well as models of oculomotor control in natural reading incorporated the idea of word frequency as the primary determinant for the speed of lexical access and substantially shaped the understanding of word processing (e.g., Engbert, Nuthmann, Richter, \& Kliegl, 2005; Grainger \& Jacobs, 1996; Jacobs, Rey, Ziegler, \& Grainger, 1998; Forster, 1976; Murray \& Forster, 2004; McClelland \& Rumelhart, 1981; Reichle, Pollatsek, Fisher, \& Rayner, 1998; Rumelhart \& McClelland, 1982).

Considering the central role of word frequency, the occurrence of the first frequency effect in ERPs is often regarded as a fingerprint for advanced lexical processing. Several ERP studies documented differential activation for low and high frequency words within the first $200 \mathrm{~ms}$ after presentation, suggesting that lexical processing relies indeed on the rapid bottom-up flow of visual properties (Braun, Hutzler, Ziegler, Dambacher; \& Jacobs, 2009; Dambacher, Kliegl, Hofmann, \& Jacobs, 2006; Hauk, Davis, Ford, Pulvermüller, \& Marslen-Wilson, 2006; Hauk \& Pulvermüller, 2004; Penolazzi, Hauk, 
\& Pulvermüller, 2007; Sereno, Brewer, \& O'Donnell, 2003; Sereno, Rayner, \& Posner, 1998).

\subsection{Predictability: top-down expectations}

Despite the undisputed importance of bottom-up processing, a purely hierarchical feedforward perspective cannot fully account for perception: Sensory input is not passively handed over from low to higher brain regions. Instead, active predictions about upcoming sensory events continuously influence the incoming signal and interact as top-down projections with earliest perceptual processes (Bar, 2007; Carlsson, Petrovic, Skare, Petersson, \& Ingvar, 2000; Churchland et al., 1994; Corbetta \& Shulman, 2002; Engel, Fries, \& Singer, 2001; Enns \& Lleras, 2008; Gilbert \& Sigman, 2007; Kastner, Pinsk, De Weerd, Desimone, \& Ungerleider, 1999; Kutas, 2006; Kveraga, Ghuman, \& Bar, 2007; McClelland \& Rumelhart, 1981; Mechelli, Price, Friston, \& Ishai, 2004; O'Connor, Fukui, Pinsk, \& Kastner, 2002; Somers, Dale, Seiffert, \& Tootell, 1999; Williams et al., 2008).

Top-down expectations play a major role in word recognition. In particular, the anticipation of an upcoming word influences stimulus processing (Altmann, 1997; Altmann \& Mirkovic, 2009; Elman, 2004; Kliegl et al., 2006; Pickering \& Garrod, 2007). For instance, readers presented with a constraining context in a cloze task (e.g., The Earth takes 365 day to orbit the ...) are usually able to predict the next word, even if it is not displayed. Obviously, visual bottom-up processing is not imperative for the activation of mental word representations when context information allows the anticipation of an upcoming stimulus. In general, there is agreement about the facilitative role of supporting contextual information for word recognition. Reaction times as well as eye movement data point to faster processing of high than of low predictability words (e.g., Ashby, Rayner, \& Clifton, 2005; Calvo \& Meseguer, 2002; Duffy, Henderson, \& Morris, 1989; Ehrlich \& Rayner, 1981; Fischler \& Bloom, 1979; Kleiman, 1980; Kliegl et al., 2004, 2006; Rayner, Ashby, Pollatsek, \& Reichle, 2004; Rayner, Binder, Ashby, \& Pollatsek, 2001; Rayner \& Well, 1996; Schuberth \& Eimas, 1977; Stanovich \& West, 1983; West \& Stanovich, 1982). The critical question, however, is when does top-down expectation of a stimulus interact with the incoming visual information during reading and, depending on whether the prediction was correct or wrong, when does it help or hurt word processing?

There have been two opposing accounts of word recognition: On the one hand, lexical access was assumed to be a rapid and automatic process that does not involve contextual information. Hence, lexical access is solely driven by bottom-up processes and context operates on a later, post-lexical level, influencing integration of semantic information into a larger discourse (e.g., Fodor, 1983; Forster, 1976; Kintsch \& Mross, 1985; Murray \& Forster, 2004). On the other hand, predictions were regarded as top-down projections that affect early processing stages in word recognition. Accordingly, sentence- and stimulus-based influences act simultaneously such that a supportive context facilitates lexical access. Word recognition therefore does not only depend on the visual stimulus but is also fostered by expectations about the identity of the incoming signal (e.g., McClelland \& Rumelhart, 1981; Morton, 1969; Rumelhart \& McClelland, 1982). Behavioral data lent support to both perspectives. Some findings suggested context effects on a purely post-lexical level (e.g., Burgess, Tanenhaus, \& Seidenberg, 1989; Lucas, 1987; Onifer \& Swinney, 1981; Swinney, 1979) whereas others pointed to rapid contextual effects on lexical access (Duffy et al., 1989; Glucksberg, Kreuz, \& Rho, 1986; Schvaneveldt, Meyer, \& Becker, 1976; Simpson, 1981; Tabossi, 1988; see Simpson, 1994, for a review).

Further insights into these interpretations were provided by the high temporal resolution of ERPs. In particular, the N400 component, a negative deflection peaking at around $400 \mathrm{~ms}$ after stimulus onset, revealed larger amplitudes for low than for high predictability words in numerous studies (Kutas \& Hillyard, 1980; for reviews see Barber \& Kutas, 2007; Kutas \& Van Petten, 1994; Kutas et al., 2006). Given its relatively late appearance in the time course, the $\mathrm{N} 400$ was sometimes considered as a pure indicator of post-lexical processing (e.g., Brown \& Hagoort, 1993; Holcomb, 1993; Misra \& Holcomb, 2003). However, other reports pointed to its sensitivity to lexical operations (e.g., Deacon, Dynowska, Ritter, \& Grose-Fifer, 2004; Deacon, Hewitt, Yang, \& Nagata, 2000; see also Lau et al., 2008; Van Petten, 1995) and demonstrated joint effects of frequency and sentential context (Dambacher et al., 2006; Van Petten \& Kutas, 1990). In fact, accumulating evidence from numerous N400 studies suggests that a modular classification of word- and sentence-level information into lexical and post-lexical processes is no longer sustainable for the understanding of word recognition. Instead, it appears that both bottom-up and top-down processes together contribute to language processing on multiple levels and at multiple time-scales (Kutas, 2006; Kutas \& Federmeier, 2011).

\subsection{Predictability and pre-activation}

Recent findings substantiate the notion that top-down expectations can also affect early levels of language processing. For instance, with the visual-world paradigm one can demonstrate that predictions about upcoming words direct behavior very rapidly. Participants listen to stories while they are viewing a display with several objects. In a scene containing, for example, a full glass of beer and an empty glass of wine (among other elements), the spoken sentence fragment "the man will drink all of ..." entailed more anticipatory saccades to the glass of beer than to the wine glass. The pattern was reversed when subjects heard the sentence "the man has drunk all of ..." (Altmann \& Kamide, 2007, 1999; see also Altmann \& Mirkovic, 2009; Kamide, Altmann, \& Haywood, 2003; Kamide, Scheepers, \& Altmann, 2003). These results suggest that contextual information is interpreted even prior to the appearance of a critical stimulus, and that knowledge-based experience guides expectations about forthcoming information.

Further, electrophysiological results indicated that representations of highly predictable words are pre-activated before they are encountered. DeLong, Urbach, and Kutas (2005) presented sentences biasing high predictability of either a vowel-initial or a consonant-initial target word (e.g., "airplane" or "kite"). Each target was preceded by the corresponding indefinite article ("an" or " $a$ "). N400 amplitudes on the article were enhanced when its phonological form mismatched the initial phoneme of the expected, but not yet visible target word (e.g., "an", when "kite" was the high predictability noun). Thus, representations of upcoming words appear to be available before they are visually presented (for similar results, see Otten, Nieuwland, \& van Berkum, 2007; Otten \& Van Berkum, 2008; Van Berkum, Brown, Zwitserlood, Kooijman, \& Hagoort, 2005; Wicha, Bates, Moreno, \& Kutas, 2003; Wicha, Moreno, \& Kutas, 2004; see also DeLong, Urbach, Groppe, \& Kutas, 2011; Federmeier \& Kutas, 1999; Federmeier, Wlotko, De Ochoa-Dewald, \& Kutas, 2007; but see Van Petten \& Luka, 2012, for a discussion).

Together, these findings suggest that the online interpretation of sentence messages affords the anticipation of words, and that expectations modulate behavior even prior to the onset of a critical stimulus. Consequently, there is room for potential interactions between top-down information and early sensory input, such that pre-activated representations of expected words affect bottom-up stimulus processing shortly after the incoming signal 
is available (cf., Gilbert \& Sigman, 2007; Grossberg, 1999; Mumford, 1992; Ullman, 1995).

\subsection{Joint effects of frequency and predictability in ERPS}

Concerning the interplay of bottom-up and top-down processes on a currently fixated word, ERP research either examined effects of frequency or of predictability, but rarely considered the joint impact of both determinants. As one exception, Van Petten and Kutas (1990) made use of ordinal word position in sentences as a proxy for increasing contextual information and reported an interaction of frequency and position on the N400 component. Indeed, the effect of word position could be linked to predictability in a later experiment with a large sentence corpus containing norms of frequency and predictability for each single word (Dambacher et al., 2006). This study confirmed an interaction of frequency and predictability for N400 amplitudes. However, effects of context were not significant in the earlier interval of the P200 component, whose amplitudes differentiated between words in the medium and high frequency range.

Evidence for early context effects was found by Penolazzi et al., (2007) who orthogonally manipulated frequency and predictability in sentences. In the interval from 110 to $130 \mathrm{~ms}$, word length interacted both with frequency and with predictability, but there was no significant interaction of frequency and predictability throughout the ERP time course. Thus, despite the indication of early contextual processing, these findings did not provide compelling evidence for a crosstalk between top-down and bottomup processes, but they were consistent with an interpretation positing that frequency-driven lexical access and context-based semantic integration are parallel and independent processes that operate on functionally dissociable systems.

Interactive patterns of context with early lexical processes were demonstrated by Sereno et al. (2003). From 132 to $192 \mathrm{~ms}$, ERPs to ambiguous words resembled those of low frequency control words, when the context biased their low frequency

Table 1

Overview of SOAs, participants, and valid epochs in Experiments 1 to 3 .

\begin{tabular}{llll}
\hline & Experiment 1 & Experiment 2 & Experiment 3 \\
\hline Display & & & \\
SOA (ms) & 700 & 490 & 280 \\
Stimulus duration (ms) & 250 & 250 & 250 \\
Blank duration (ms) & 450 & 240 & 30 \\
Participants & & & \\
$N$ & 32 (one excluded) & 32 & 32 \\
Female/male & $28 / 4$ & $22 / 10$ & $24 / 8$ \\
Mean age (SD) & $23.3(6.0)$ & $24.3(3.1)$ & $27.3(6.8)$ \\
$N$ right-handed & 28 & 27 & 29 \\
Valid epochs (\%) & $89.4 \%$ & $97.4 \%$ & $92.6 \%$ \\
\hline
\end{tabular}

meaning; they were similar to those of high frequency control words in a neutral context that was believed to a ctivate the high frequency meaning of the ambiguous stimulus. The authors proposed that context supported the selection of the appropriate meaning early in the time course (see also Van Petten, 1995). Furthermore, a marginal context effect on low frequency control words suggested an influence on lexical processing of any unambiguous word.

In summary, evidence for contextual effects on lexical processing has been found early and late in the time course of word recognition, but there are also reports of additive effects. Thus, the enabling conditions in the interplay of bottom-up and top-down information in reading are still in need of further clarification.

\subsection{Present study}

The goal of the present study was twofold: We aimed (1) to establish further the joint timeline of frequency and predictability effects during word recognition by (2) taking also into account effects of presentation rate. Specifically, we manipulated SOAs across three otherwise identical experiments (total $N=96$ participants). Experiments 1 and 2 presented sentences with SOAs of 700 and $490 \mathrm{~ms}$, respectively. These values correspond to the upper and lower ranges of display rates that are typically used in ERP reading studies. As pointed out above, these paces are slower than the normal reading speed. To test whether the timeline obtained with such low presentation rates generalizes to a natural reading rate, the SOA was further reduced to a value of only $280 \mathrm{~ms}$ in Experiment 3.

Stimuli in all experiments consisted of pairs of low and high frequency target words, which were embedded in neutral sentence frames. The predictability of the target word was manipulated by a preceding context sentence, which biased the reader to expect either the low or the high frequency word. This allowed us to manipulate frequency and predictability orthogonally within otherwise identical sentence frames (see Tables 1 and 2 for an overview of methods and stimuli in the three experiments, respectively).

\section{Experiment 1}

Experiment 1 investigated the time course of bottom-up and top-down information with an SOA of $700 \mathrm{~ms}$. We expected an interaction of frequency and predictability, if a supporting context facilitates frequency-based lexical processing early in the time course (cf., Sereno et al., 2003). Alternatively, additive effects of frequency and predictability would be consistent with the speculation that the two variables reflect independent systems (cf., Penolazzi et al., 2007).

Table 2

Descriptive statistics of target words.

\begin{tabular}{|c|c|c|c|c|c|c|c|c|}
\hline & \multicolumn{4}{|c|}{ High frequency } & \multicolumn{4}{|c|}{ Low frequency } \\
\hline & \multicolumn{2}{|c|}{ High predictability } & \multicolumn{2}{|c|}{ Low predictability } & \multicolumn{2}{|c|}{ High predictability } & \multicolumn{2}{|c|}{ Low predictability } \\
\hline Word form freq. & 155.6 & 194.6 & 155.6 & 194.6 & 3.8 & 2.1 & 3.8 & 2.1 \\
\hline Lemma freq. & 362.2 & 875.3 & 362.2 & 875.3 & 4.9 & 2.7 & 4.9 & 2.7 \\
\hline Predictability & .84 & .13 & .01 & .02 & .83 & .13 & .01 & .02 \\
\hline Word position & 6.94 & .76 & 6.94 & 0.76 & 6.94 & .76 & 6.94 & .76 \\
\hline Word class & \multicolumn{6}{|c|}{ noun pairs: $N=92 ;$ verb pairs: $N=37 ;$ adjective pairs: $N=15$} & & \\
\hline
\end{tabular}




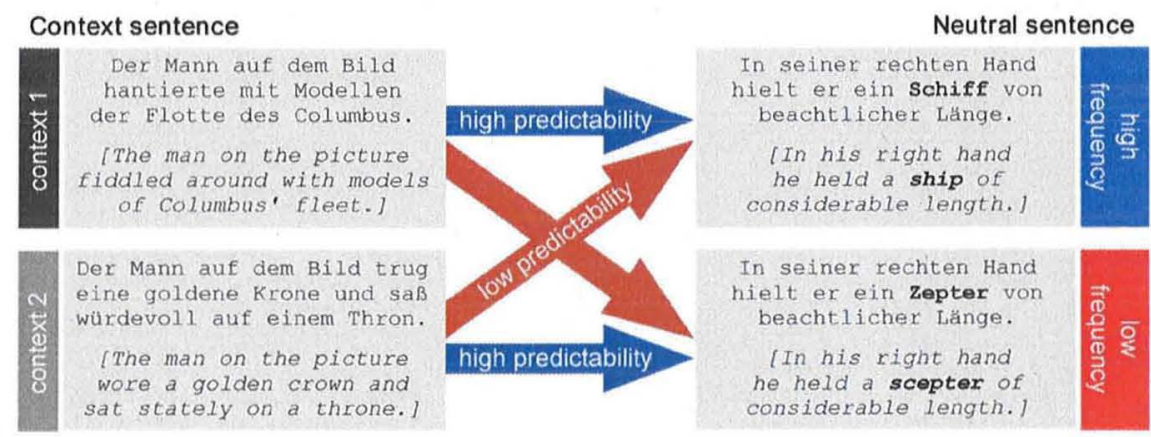

Fig. 1. Stimulus example. Pairs of low and high frequency target words (bold) were embedded in neutral sentence frames. A preceding context sentence established high predictability of either the high or the low frequency target, while its counterpart was of low predictability. A total of 144 sentence units set up a two-by-two factorial manipulation of frequency and predictability.

\subsection{Methods}

\subsubsection{Participants}

Thirty-two native speakers of German (28 female; 28 righthanded; mean age: 23.3, SD: 6.0 ) recruited at the Freie Universität Berlin received course credit or 8 Euros per hour for participation. They had normal or corrected-to-normal vision, and reported no history of neurological illness.

\subsubsection{Materials}

A total of 144 sentence units (Potsdam Sentence Corpus 3) formed the stimulus materials (see Fig. 1 for an example). Each unit comprised two context sentences and one neutral sentence. Pairs of high (e.g., ship) and low frequency (e.g., scepter) target words were embedded in the neutral sentences. Predictability on target words was triggered by the prior context sentence: High frequency targets were of high predictability in context 1 and of low predictability in context 2 . In turn, low frequency targets were of low predictability in context 1 and of high predictability in context 2 . Thus, the stimuli realized an orthogonal manipulation of frequency and predictability within otherwise identical sentences frames. The randomized stimuli were divided into lists according to a Latin square design such that every participant was presented with only one version of each sentence unit. Further details on the stimuli are depicted in Fig. 1 and described in the following paragraphs (see also Table 2).

Frequency norms. Target word pairs consisting of a high and a low frequency open-class word were selected from the dlexDB data base (Heister et al., 2011; based on the DWDS corpus, Geyken, 2007). High frequency words comprised lemma and word form frequencies greater than 100 and 10 occurrences per million, respectively. For low frequency words, lemma and word form frequencies amounted to less than 10 per million. High and low frequency words from one pair were members of the same class (i.e., nouns, verbs, or adjectives) and, where possible, shared the same number of letters; they differed in one letter in 19 of the 144 cases, in two letters in 4 cases and in three letters in 1 case. Target length varied between three and eight letters and was matched across conditions.

Neutral sentences. A neutral sentence was then constructed for each of the 144 target pairs. This sentence was identical for the two words from one pair. In order to reduce potential effects of word position in sentences (Dambacher et al., 2006; Kuperman, Dambacher, Nuthmann, \& Kliegl, 2010), targets occurred only at positions six, seven, or eight and were always followed by at least two more words, such that they never appeared at the sentencefinal position. Neutral sentence length ranged from 9 to 12 words (mean: 10.47; SD:.82).
Context sentences. Two context sentences were created for each neutral sentence. Context 1 biased high predictability of the high frequency target word, while the low frequency word was of low predictability. Context 2 triggered high predictability of the low frequency word, while the high frequency word was of low predictability. Context sentences had a length of 3 to 18 words (mean: 11.48; SD: 2.81).

Predictability norms. A total of 151 volunteers took part in an independent cloze task for the collection of predictability norms; none of them participated in the EEG experiments. Every participant worked through a part of the stimulus materials, such that each sentence was rated by at least 30 judges. For the cloze procedure, stimuli were divided into two lists so that each subject was presented with only one context together with the corresponding neutral sentence. Sentences were visually presented up to the word prior to the target. Participants were then asked to write at least one and no more than three words probably occurring on the next position. Predictability was computed as proportion of participants correctly predicting the target word with one of their answers. Sentences entered stimulus materials only if both low and high frequency words reached cloze values larger than .5 in their high predictability contexts and, at the same time, did not exceed 1 in their low predictability conditions. While targets were syntactically and semantically correct words in neutral sentences across all conditions, low predictability words were naturally less expected. Accordingly, an independent rating study on the plausibility of target words ( $N=40$ participants; seven-point Likert scale from -3 to +3 ; low-frequency - low predictability: mean $=-.34$, $\mathrm{SE}=.16$; low-frequency - high predictability: mean $=1.27, \mathrm{SE}=.19$; high-frequency - low predictability: mean $=-.36, \mathrm{SE}=.15$; highfrequency - high predictability: mean $=1.20, \mathrm{SE}=.18$ ) revealed higher values for high than for low predictability words $[F(1,143)=1577$; $p<.01]$ while plausibility differences between frequency categories $[F(1,143)=2.43 ; p=.12]$ or the interaction of frequency $x$ predictability were not reliable $[F(1,143)=1.35 ; p=.25]$.

\subsubsection{Procedure}

Participants were seated at a distance of $60 \mathrm{~cm}$ from a 21" monitor (resolution: $1024 \times 768$; refresh rate: $100 \mathrm{~Hz}$ ) in a dimly lit room and were asked to silently read the two-sentence stories for comprehension. A trial started with the message "Bereit machen ..." ["Get ready..."] for $1000 \mathrm{~ms}$, followed by a $500 \mathrm{~ms}$ blank screen. A context sentence was then displayed in its entirety in one or two lines until participants pressed a button. Thereafter, a fixation cross (preceded and followed by $500 \mathrm{~ms}$ blank screens) indicated for $1000 \mathrm{~ms}$ the required fixation position in the center of the monitor. The stimuli of the neutral sentence together with their adjacent punctuation were then presented word by word (RSVP) with an SOA 
of $700 \mathrm{~ms}$ (i.e., $250 \mathrm{~ms}$ stimulus duration; $450 \mathrm{~ms}$ blank screen). After another 500 ms blank, either the next trial was initiated (two thirds of the trials) or a three-alternative multiple-choice question tested sentence comprehension (one third of the trials). Questions referred equally often to the content of the context and of the neutral sentence, but never to the target word itself.

Participants were asked to avoid eye movements and blinks during the phase of word-wise sentence presentation. Eight practice trials familiarized them with the task; they took a short break after half of the main experiment. Sentences (font: Courier New; size: 18pt) were presented in black on a white background and in randomized order.

\subsubsection{EEG recording}

EEG data were recorded from 50 scalp locations of the 10/10 international system (Fp1/2, AF3/z/4, F7/5/3/1/z/2/4/6/8, FC5/3/z/ 4/6, T7/8, C5/3/1/z/2/4/6, CP5/3/z/4/6, P7/5/3/1/z/2/4/6/8, PO7/3/ $\mathrm{z} / 4 / 8,01 / \mathrm{z} / 2$ ) using a 64-channel elastic electrode cap (ElectroCap Int.) and a 64-channel amplifier (Porti-S/64, TMS Int.). Impedances were kept below $10 \mathrm{k} \Omega$. EEG electrodes were referenced against the left mastoid (M1) during recording, and rereferenced to the average of all scalp electrodes offline. In addition, four electrodes placed at the outer canthus of each eye and above and below the left eye were used to record the electrooculogram (EOG) in a bipolar montage to monitor for eye movements and blinks. Data were continuously recorded at a rate of $512 \mathrm{~Hz}$ and down-sampled to $500 \mathrm{~Hz}$ offline. Amplifier settings cut of frequencies below 0.01 and above $100 \mathrm{~Hz}$ online. Data were bandpass filtered offline from 0.2 to $30 \mathrm{~Hz}$.

\subsubsection{Data processing and analyses}

The continuous EEG signal was divided into epochs from $200 \mathrm{~ms}$ before and $700 \mathrm{~ms}$ after target word onset. Data were corrected relative to a $100 \mathrm{~ms}$ pre-stimulus baseline. An automatic algorithm rejected segments with an absolute amplitude value larger than $80 \mu \mathrm{V}$ in at least one channel. Artifact correction resulted in a loss of $10.6 \%$ of target epochs. Data of one subject were excluded because more than $50 \%$ of the trials were contaminated by artifacts. From the remaining data, single-subject average ERPs were generated for each condition.

For analyses, mean ERP amplitudes were computed in three time windows from 140 to $210 \mathrm{~ms}, 240$ to $300 \mathrm{~ms}$, and 300 to $500 \mathrm{~ms}$. These intervals were chosen so that they comprised prominent peaks in the ERP waveform corresponding to the posterior N1, P2, and N400 components, respectively. Global analyses of variance (ANOVAs) with within-subject factors frequency (2), predictability (2), and electrode (50) were calculated in each of the time windows. Note that the average reference sets mean amplitudes across all scalp electrodes to zero, such that only effects in interaction with the factor electrode are meaningful in these ANOVAs; interactions of frequency or predictability with the factor electrode are reported as main effects. Significant results in the global ANOVAs were further scrutinized in ANOVAs on selected electrodes. Where appropriate, the Huynh-Feldt correction was applied to adjust degrees of freedom (rounded down) and $p$-values for violations of the sphericity assumption. Data were visualized with selected functions of the EEGLAB toolbox (Delorme \& Makeig, 2004).

\subsection{Results}

Fig. 2 displays grand average ERP curves for the four experimental conditions of frequency (low/high) and predictability (low/high) on 50 scalp electrodes. Target words evoked a prominent $\mathrm{P} 1$ at posterior sites after $110 \mathrm{~ms}$. The $\mathrm{N} 1$ peaked at around $170 \mathrm{~ms}$ and was followed by the P2 at approximately $280 \mathrm{~ms}$.
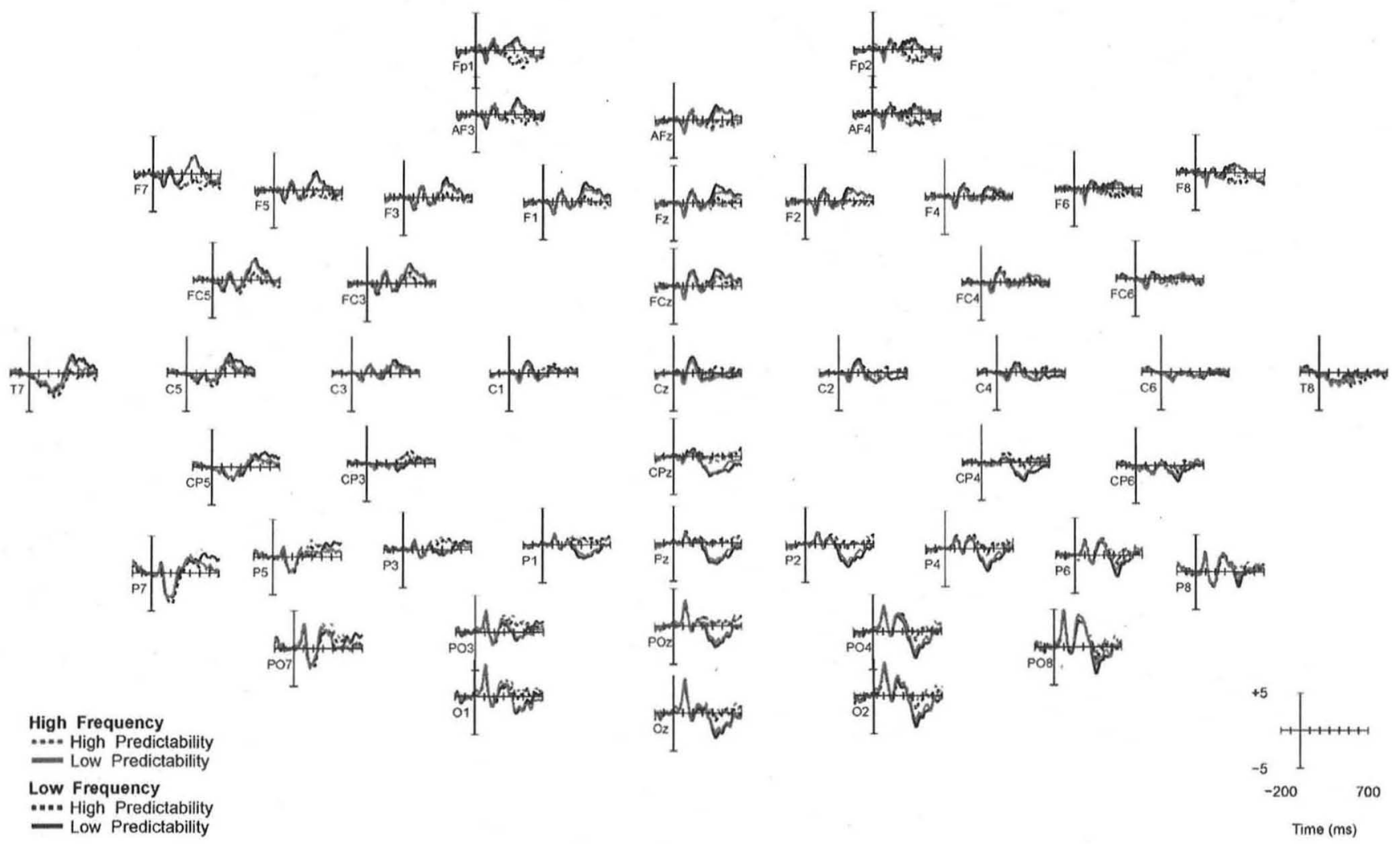

Fig. 2. Grand average ERPs to target words in Experiment 1 (SOA of $700 \mathrm{~ms}$ ). ERPs are shown for the four experimental conditions of frequency (low, high) and predictability (low, high) on 50 scalp electrodes. 

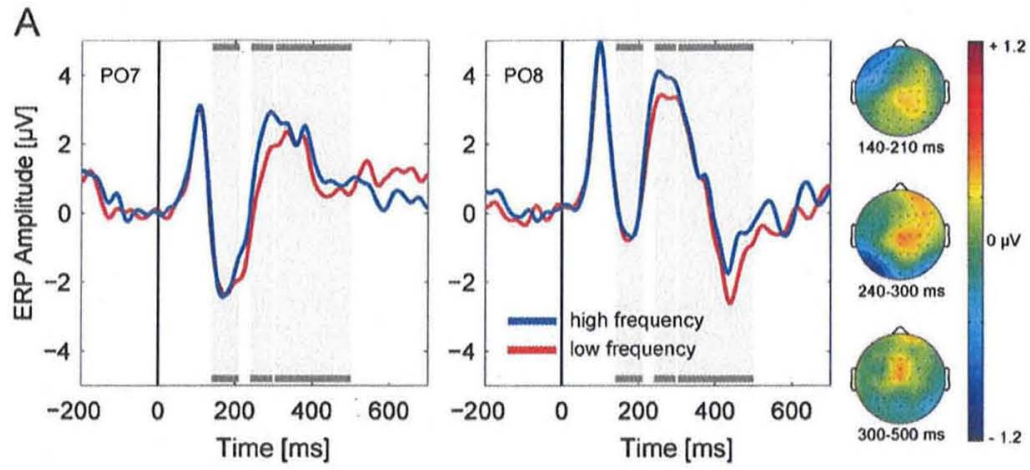

B

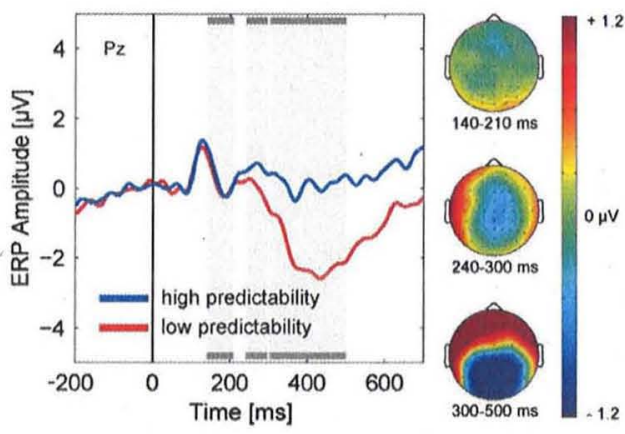

Fig. 3. Grand average ERPs for selected electrodes in Experiment 1 (SOA of $700 \mathrm{~ms}$ ). ERPs for (A) frequency and (B) predictability conditions are shown together with the scalp topographies of the corresponding effects (low minus high) in analyzed time windows (gray bands).

The N400 emerged as a broad negative deflection peaking after $430 \mathrm{~ms}$.

\subsection{1. $N 1$}

In the epoch from 140 to $210 \mathrm{~ms}$, neither predictability nor the interaction of frequency and predictability were significant in the global ANOVA across all electrodes $(F$ 's $<1)$. Frequency revealed a statistical trend $[F(3,97)=2.248 ; p=.083]$. Yet, the topography (Fig. 3(A)) was markedly different from the frequency effects in later components and experiments (see below). Furthermore, onset analyses in Experiment 1 did not reveal significant frequency effects in this time window (see 5. Comparison between experiments). Therefore, this trend was not further pursued here.

\subsection{2. $P 2$}

From 240 to $300 \mathrm{~ms}$, the global ANOVA yielded significant effects of frequency $[F(4,135)=4.027 ; p=.003]$ and predictability $[F(3,108)=3.178 ; p=.020]$; the interaction was not reliable $(F<1)$. For word frequency (low minus high), Fig. 3(A) illustrates negative amplitude differences at posterior electrodes with a trend towards left-hemispheric sites. The effect was positive at frontal and central channels over the right hemisphere. Post-hoc comparisons on averaged channels PO7/8 confirmed more positive amplitudes for high than for low frequency words $[F(1,30)=$ 20.538; $p<.001$.

Word predictability exerted a negative effect (low minus high) on central channels (Fig. 3(B)). Amplitudes were more negative for low than for high predictability words on channel $\mathrm{Pz}[F(1$, $30)=9.360 ; p=.005]$. Considering the scalp topography and the ERP time course, this predictability effect presumably reflects an early phase of the N400 component.

\subsection{3. $N 400$}

From 300 to $500 \mathrm{~ms}$, predictability was highly significant in the global ANOVA $[F(3,112)=35.256 ; p<.001]$. The effect was distributed over centro-parietal channels (Fig. 3(B)). A post-hoc comparison on electrode $\mathrm{Pz}$ attested significantly more negative amplitudes for low than for high predictability words $[F(1,30)=129.156 ; p<.001]$ Neither frequency $[F(3,112)=1.604 ; p=.182]$ nor the interaction of frequency and predictability $[F(4,125)=1.035 ; p=.394]$ were reliable.

\subsection{Discussion}

Examining the time course of frequency and predictability effects with an SOA of $700 \mathrm{~ms}$, the data of Experiment 1 revealed the first reliable frequency effect on ERP amplitudes in the interval between 240 and $300 \mathrm{~ms}$. High frequency words evoked more positive P2 amplitudes than low frequency words. In the same interval, a predictability effect with central scalp distribution denoted the beginning of the $\mathrm{N} 400$ effect. Thus, the observed frequency effect coincided with an early phase of the N400. However, emerging over posterior electrodes the scalp distribution of the frequency effect was dissimilar to the typical N400, such that frequency and predictability may have affected distinct neural processes. Indeed, the interaction between the two variables on P2 amplitudes was not significant. The additive pattern is in agreement with previous research. Using an SOA of $700 \mathrm{~ms}$, Penolazzi et al. (2007) reported independent effects of frequency and predictability throughout the ERP time course. Similarly, frequency and predictability effects were temporally overlapping and additive in the present experiment.

In accordance with numerous other ERP studies, N400 amplitudes were larger for low than for high predictability words. Frequency, though, did not significantly affect the N400 from 300 to $500 \mathrm{~ms}$, neither as a main effect nor in interaction with predictability. This appears at odds with previous reports of interactive patterns between context and frequency on the N400 (Dambacher et al., 2006; Van Petten \& Kutas, 1990). Van 
Petten and Kutas found larger amplitudes for low than for high frequency words only at early positions in sentences; the effect disappeared as sentences unfolded. Taking ordinal word position as an estimate for sentential information, the authors concluded that frequency affects N400 amplitudes predominantly when contextual constraint is weak, as is the case at the beginning of sentences. In the present experiment, sentences always biased a specific target occurring at word position six to eight in the sentence. Thus, the constraining sentence frames may have neutralized effects of frequency on the N400. Further, our targets implemented a factorial manipulation of frequency and predictability in highly controlled sentences, whereas the corpus-analytic studies from Van Petten and Kutas (1990) and Dambacher et al. (2006) made use of natural variations of inter-correlated word properties, potentially resulting in larger variance of effects (e.g., due to correlations between predictability and frequency, or between frequency and word length). As it stands, the effect of frequency on the N400 is not yet resolved; there are some studies showing amplitude modulations (e.g., Penolazzi et al., 2007; Rugg, 1990) whereas others do not (e.g., Brown, Hagoort, \& ter Keurs, 1999; Hauk \& Pulvermüller, 2004).

\section{Experiment 2}

Experiment 1 with an SOA of $700 \mathrm{~ms}$ yielded additive effects of frequency and predictability in overlapping intervals. Several sentence reading studies using somewhat faster presentation rates of around two words per second, however, reported evidence for context-based pre-activation of stimuli (e.g., DeLong et al., 2005; Wicha et al., 2004). Although still slower than normal reading, this timing is closer to natural fixation durations. To test if such a display rate alters the timeline of lexical processing, an SOA of $490 \mathrm{~ms}$ was used in Experiment 2.

\subsection{Methods}

\subsubsection{Participants}

Thirty-two native German readers at the Freie Universität Berlin participated in Experiment 2 (22 female; 27 right-handed; mean age: 24.3 , SD: 3.1 ). They had normal or corrected-to-normal vision and reported no history of neurological disease. None of the subjects took part in Experiments 1 or 3 .

\subsubsection{Stimuli and procedure}

Participants read the same sentences as in Experiment 1. As before, neutral sentences were successively displayed for $250 \mathrm{~ms}$ in the center of the screen. However, the presentation of consecutive words was now separated by blank screen of only $240 \mathrm{~ms}$, resulting in an SOA of $490 \mathrm{~ms}$.

\subsubsection{EEG recording}

Data recording and filtering was identical to Experiment 1 , except for the amplifier and electrode cap: In Experiment 2, data were recorded with a 64-channel amplifier (BrainAmp MR professional, Vision Recorder 1.10, BrainProducts, Munich) at a sampling rate of $500 \mathrm{~Hz}$ and with a time constant of $10 \mathrm{~Hz}$. Data were assessed from the same electrodes as in Experiment 1, and in addition from channels Fpz, AF7/8, FT9/10, PO9/10, and Iz. Electrodes below the eyes and at the left and right outer canthi
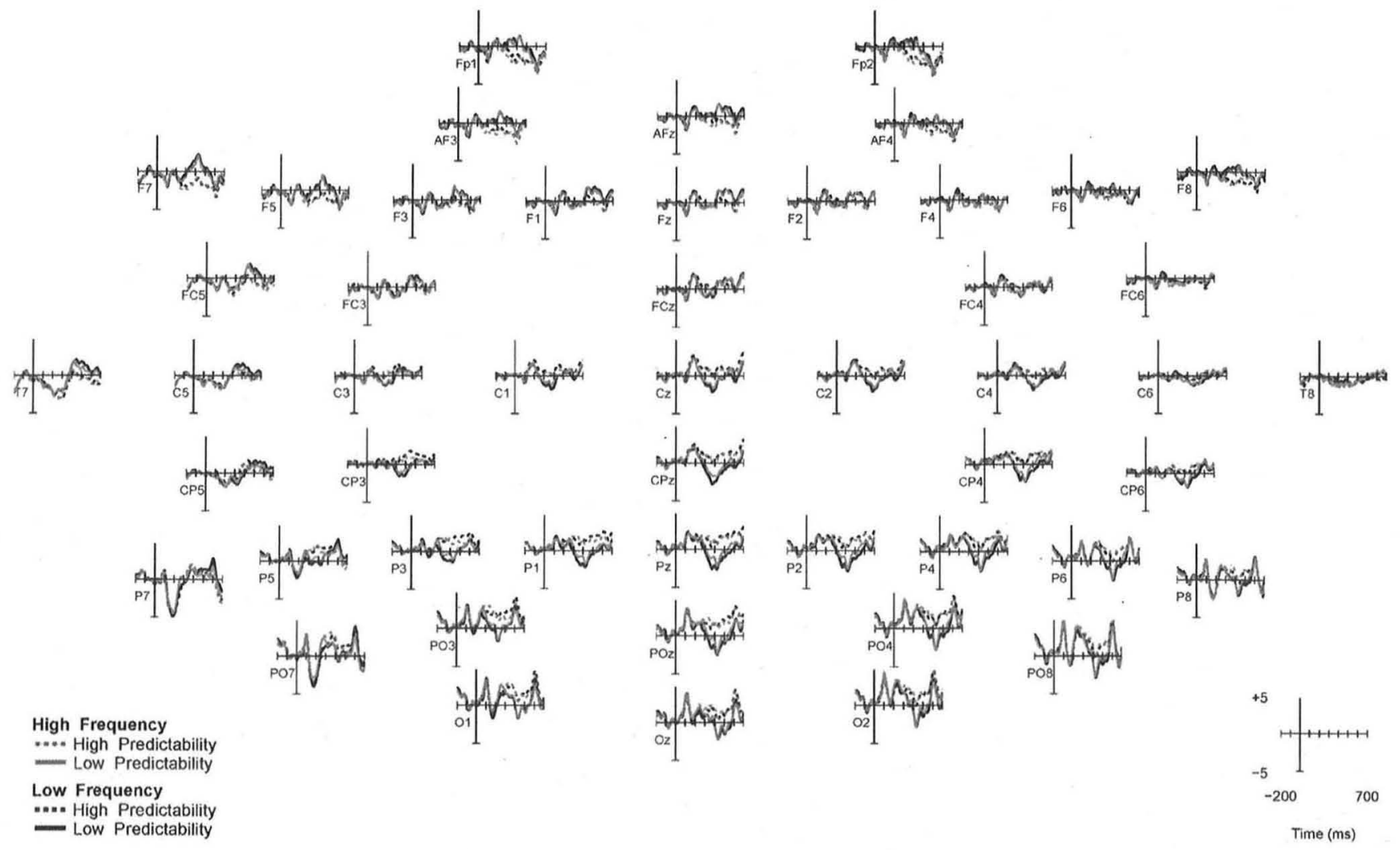

Fig. 4. Grand average ERPs to target words in Experiment 2 (SOA of $490 \mathrm{~ms}$ ). ERPs are shown for the four experimental conditions of frequency (low, high) and predictability (low, high) on 50 scalp electrodes. 

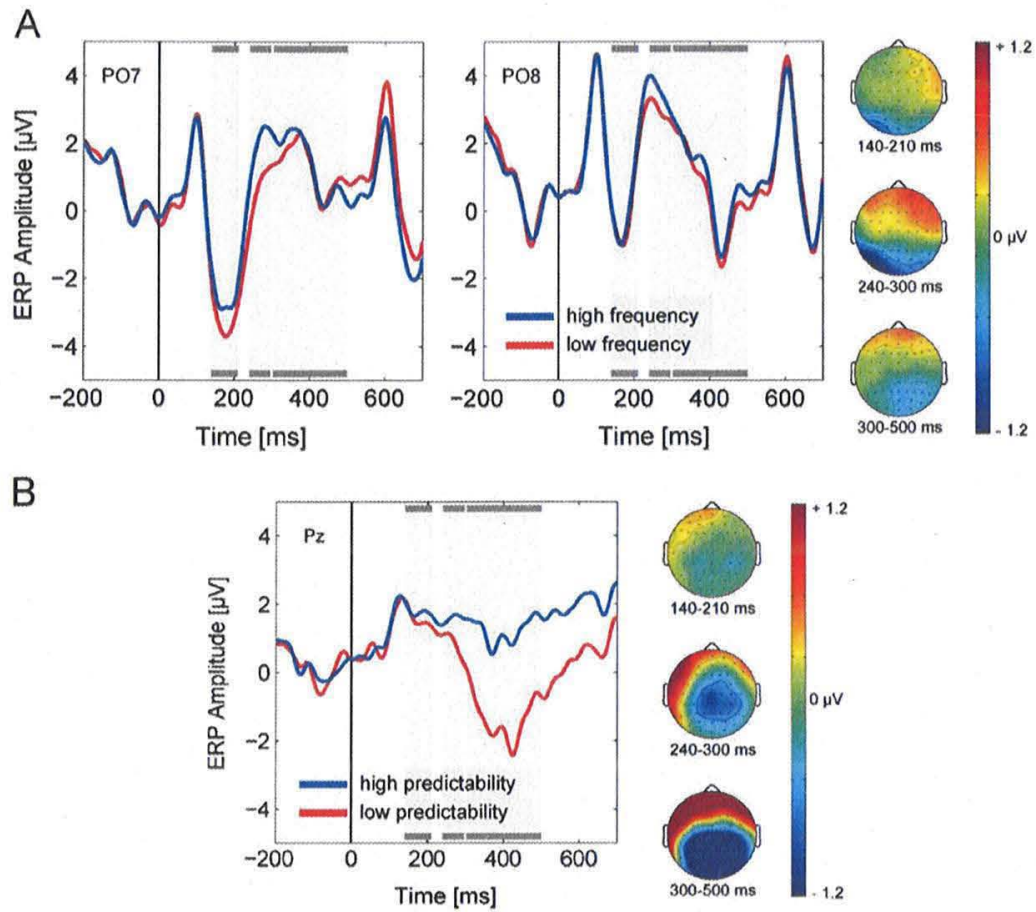

Fig. 5. Grand average ERPs on selected electrodes in Experiment 2 (SOA of $490 \mathrm{~ms}$ ). ERPs for (A) frequency and (B) predictability conditions are shown together with scalp topographies of corresponding effects (low minus high) in analyzed time windows (gray bands).

recorded the EOG. The channels were referenced to the left mastoid during recording and average re-referenced offline.

In Experiment 2, fixation position was simultaneously recorded with a video-based eye tracker (IView X Hi-Speed; SensoMotoric Instruments $\mathrm{GmbH}$, Germany) and synchronized with the EEG record (Dimigen, Valsecchi, Sommer, \& Kliegl, 2009). Eye tracking data were recorded for different purposes and are not reported here. Concurrent operation of the eye tracker did not interfere with the EEG recording.

\subsubsection{Data processing and analyses}

Processing and analysis of the EEG data was the same as in Experiment 1. Artifact rejection resulted in an elimination of $2.7 \%$ of target trials. As for Experiment 1, three time intervals captured the $\mathrm{N} 1(140-210 \mathrm{~ms})$, the P2 $(240-300 \mathrm{~ms})$, and the $\mathrm{N} 400$ component (300-500 ms). Mean amplitudes in the epochs were submitted to global ANOVAs on within-subject factors frequency (2), predictability (2), and electrode (62).

\subsection{Results}

Visual inspection of the ERP course showed the P1 peaking at around $110 \mathrm{~ms}$, followed by the $\mathrm{N} 1$ at $170 \mathrm{~ms}$ at posterior sites, and the P2 after around $270 \mathrm{~ms}$. The $\mathrm{N} 400$ had its maximum after approximately $430 \mathrm{~ms}$ (Fig. 4).

\subsection{1. $N 1$}

From 140 to $210 \mathrm{~ms}$, the global ANOVA yielded no significant effects of predictability $[F(4,134)=1.142 ; p=.340]$ or of the frequency $x$ predictability interaction $[F(4,134)=1.874$ $p=.122]$. A marginally significant effect of frequency $[F(4$ $146)=2.080 ; p=.075]$ reflected larger (i.e., more negative) amplitudes for low than for high frequency words at left posterior sites (Fig. 5(A)). The topography of these amplitude differences showed a similar, though less pronounced distribution to the later frequency effect on the P2 (see below). We therefore tested whether amplitude differences on the $\mathrm{N} 1$ were already reliable on single electrodes. Indeed, the post-hoc comparison of amplitudes for low and high frequency words on averaged channels PO7/8 was significant $[F(1,31)=5.409 ; p=.027]$.

\subsection{2. $P 2$}

The global ANOVA in the epoch from 240 to $300 \mathrm{~ms}$ yielded significant effects of frequency $[F(4,145)=8.004 ; p<.001]$ and predictability $[F(3,120)=9.436 ; p<.001]$, but no interaction $[F(5$, $176)=1.011 ; p=.418$ ]. For frequency, the scalp distribution showed negative amplitude differences at posterior left sites while they were positive at frontal channels. Thus, compatible with the findings of Experiment 1, amplitudes were more positive for high than for low frequency at posterior electrodes (Fig. 5(A)). Post-hoc comparisons on averaged channels PO7/8 yielded a highly significant effect $[F(1,31)=27.128 ; p<.001]$.

The word predictability effect was distributed over centroparietal electrode sites. Amplitudes were more negative for low than for high predictability words, (Fig. 5(B)), which was confirmed in a post-hoc test on channel $\mathrm{Pz}[F(1,31)=16.143 ; p<.001]$. As in Experiment 1, this effect presumably reflected an early phase of the N400.

\subsection{3. $N 400$}

From 300 to $500 \mathrm{~ms}$, the predictability effect was significant in the global ANOVA $[F(2,67)=50.653 ; p<.001]$. Over centroparietal electrodes, amplitudes were more negative for low than for high predictability words (Fig. 5(B)). The post-hoc comparison on channel $\mathrm{Pz}$ was significant $[F(1,31)=85.621 ; p<.001]$. Neither frequency $[F(3,106)=2.090 ; p=.097]$ nor the frequency $x$ predictability interaction $[F(4,132)=1.731 ; p=.142]$ were reliable in the global ANOVA. 


\subsection{Discussion}

Using an SOA of $490 \mathrm{~ms}$, Experiment 2 essentially replicated the pattern obtained in Experiment 1 (SOA of $700 \mathrm{~ms}$ ). Frequency and predictability affected ERP amplitudes in an interval from 240 to $300 \mathrm{~ms}$. The effect of frequency manifested itself as a more positive P2 amplitudes for high than for low frequency words. Notably, we observed a marginal frequency effect in an earlier interval from 140 to $210 \mathrm{~ms}$, a latency that is in agreement with previous reports (e.g., Dambacher et al., 2006; Hauk \& Pulvermüller, 2004). The trend was significant on single channels and yielded a scalp distribution that was similar to the frequency effect later in the time course. This finding suggests that lexical processing started already before $200 \mathrm{~ms}$; we will return to this issue in 5. Comparison between experiments.

Amplitude differences in response to predictability had a central scalp distribution on the $\mathrm{P} 2$, presumably reflecting an early phase of the N400 that showed a strong predictability effect over centro-parietal electrodes but no effect of frequency (see Discussion of Experiment 1). Hence, as in Experiment 1, there was no significant interaction of frequency and predictability throughout the ERP time course (cf., Penolazzi et al., 2007).

\section{Experiment 3}

Experiments 1 and 2 yielded additive effects of frequency and predictability. Of course, the failure to obtain a significant interaction between these factors does not rule out crosstalk, but it also does not provide compelling evidence for an interplay of top-down expectations with bottom-up processing. Yet, studies reporting rapid context effects are often based on natural reading or speech perception (e.g., Altmann \& Kamide, 2007; Kliegl et al., 2006; Van Berkum et al., 2005). Perhaps such normal conditions encourage rapid processing. To test this option, a near-natural presentation rate was used in Experiment 3. Stimulus presentation of $250 \mathrm{~ms}$ and inter-stimulus intervals of $30 \mathrm{~ms}$ approximated the duration of fixations and inter-word saccades in normal reading (Rayner, 2009; Rayner et al., 2012). Importantly, in our sentence materials, the problem of overlapping components from consecutive stimuli at high rates is minimized since words preceding and following targets are physically identical in all conditions.

We considered two possible outcomes. On the one hand, evidence for later N400 onsets at short SOAs (Kutas, 1987; Robichon et al., 2002) suggests that word recognition is delayed in comparison with long SOAs because rapid presentation of words affords less time for processing of the current and prediction of upcoming words. In this case, as in Experiments 1 and 2, frequency and predictability should yield additive effects, possibly with longer latencies. On the other hand, considering frequency and predictability effects on fixation durations (e.g., Kliegl et al., 2006), a near-normal rate may engage fast word recognition because it strongly limits the time available for stimulus processing and because it approximates temporal conditions that may be optimal for natural reading. In this case, a high presentation rate might accelerate processing and trigger the involvement of context-based information to grant rapid lexical access.

\subsection{Methods}

\subsubsection{Participants}

Thirty-two native German readers (24 female; 29 righthanded; mean age: 27.3, SD: 6.8) at the Freie Universität Berlin
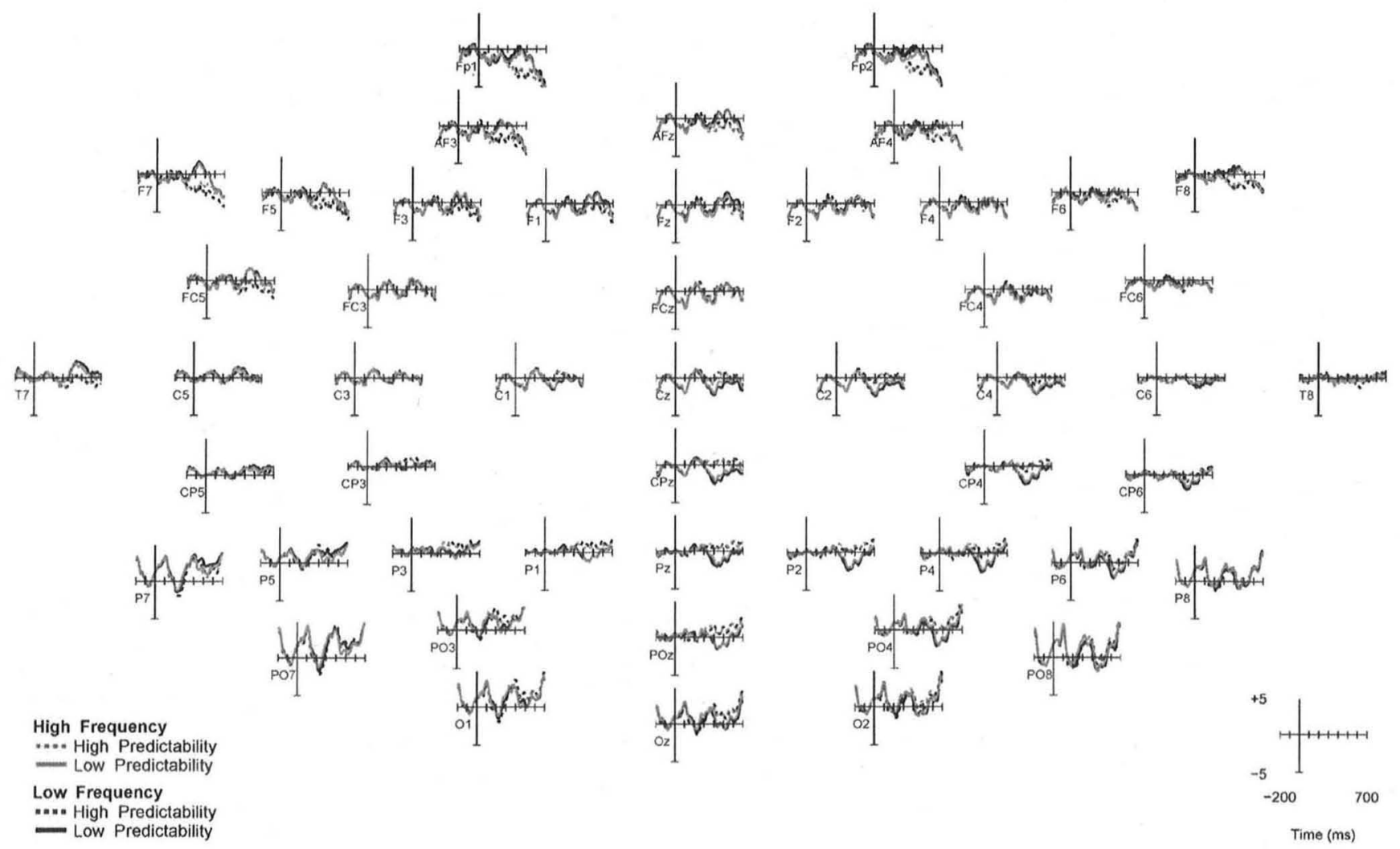

Fig. 6. Grand average ERPs to target words in Experiment 3 (SOA of $280 \mathrm{~ms}$ ). ERPs are shown for the four experimental conditions of frequency (low, high) and predictability (low, high) on 50 scalp electrodes. 

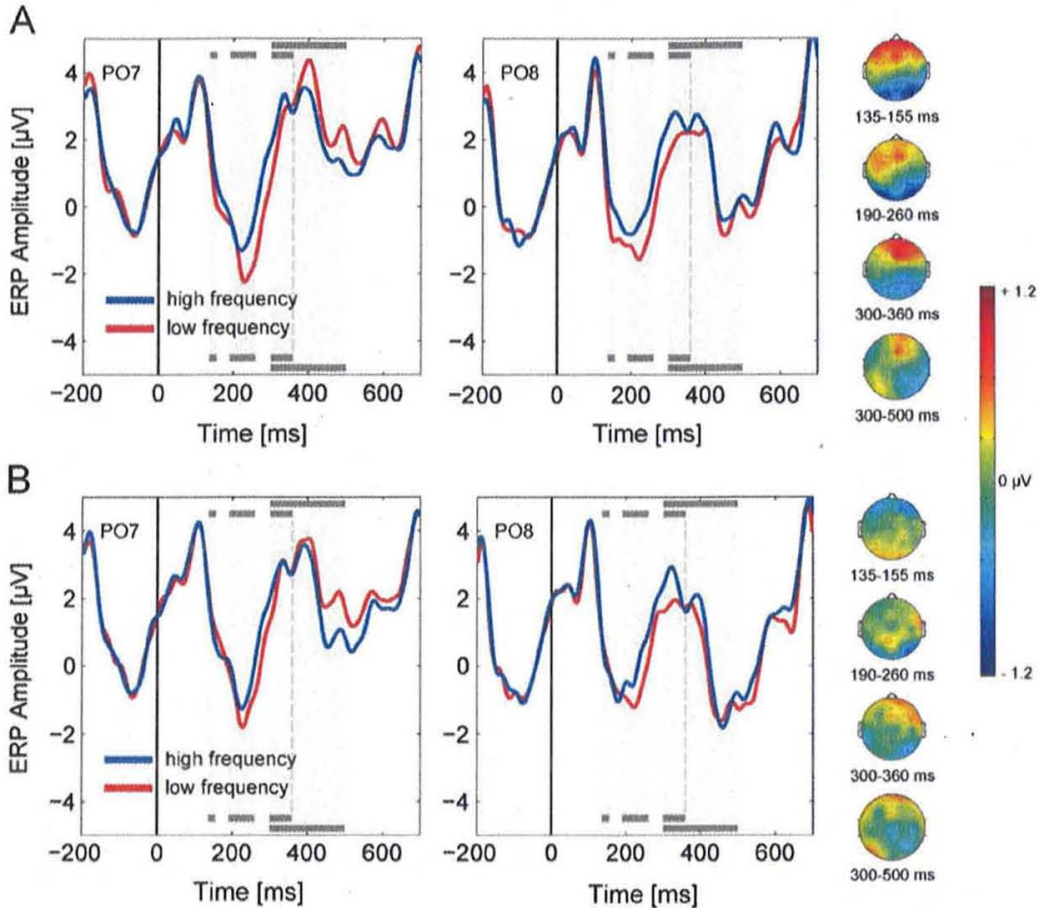

C

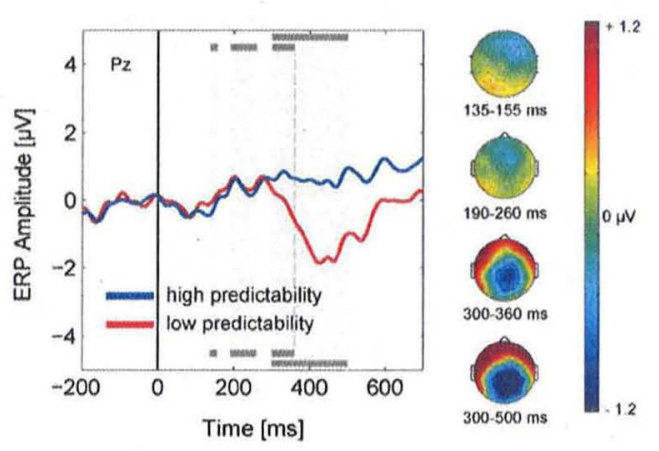

Fig. 7. Grand average ERPs on selected electrodes in Experiment 3 (SOA of $280 \mathrm{~ms}$ ). ERPs for (A) frequency conditions of high predictability words, (B) frequency conditions of low predictability words, and $(C)$ predictability conditions are shown together with scalp topographies of corresponding effects (low minus high) in analyzed time windows (gray bands).

received course credit for participation. They had normal or corrected-to-normal vision and reported no history of neurological disease. None of them took part in Experiments 1 or 2.

\subsubsection{Stimuli and procedure}

Stimuli were the same as in Experiments 1 and 2. As in the previous experiments, the words of the neutral sentences were successively displayed for $250 \mathrm{~ms}$ in the center of the screen. However, the consecutive words were separated by a blank screen of only $30 \mathrm{~ms}$ duration, resulting in an SOA of $280 \mathrm{~ms}$.

\subsubsection{Apparatus, EEG recording, data processing, and analyses}

Apparatus and recording procedures were identical to Experiment 1 . Data were processed and analyzed analogously. Artifact rejection resulted in an elimination of $7.4 \%$ of target epochs.

Visual inspection of ERPs revealed a time course that was temporally shifted relative to Experiments 1 and 2. For statistical analyses, we therefore adjusted the time intervals so that they captured corresponding ERP components: For amplitudes of the
$\mathrm{N} 1$ and P2, epochs from 190 to $260 \mathrm{~ms}$ and from 300 to $360 \mathrm{~ms}$ were chosen, respectively. Notably, the latter lay in the N400 time window from 300 to $500 \mathrm{~ms}$, which remained unchanged with respect to Experiments 1 and 2 . In addition, an early and transient negative deflection at around $145 \mathrm{~ms}$ (eN1) was analyzed in an interval from 135 to 155 ms. Mean amplitudes in time intervals were submitted to global ANOVAs on within-subject factors frequency (2), predictability (2), and electrode (50).

\subsection{Results}

As in Experiments 1 and 2, the P1 peaked after around $110 \mathrm{~ms}$ (Fig. 6), whereas visual inspection of the subsequent time course revealed differences in the ERP morphology compared to the previous experiments. First, after around $145 \mathrm{~ms}$, a negative deflection peaked over right parietal electrodes and evolved into a short-living plateau on left parietal and anterior channels; for the remainder of this paper, we shall call this early constituent of the double-peaked waveform early N1 or eN1. No similar deflection was observed in Experiments 1 or 2 (see Fig. 8(A)). Second 
A
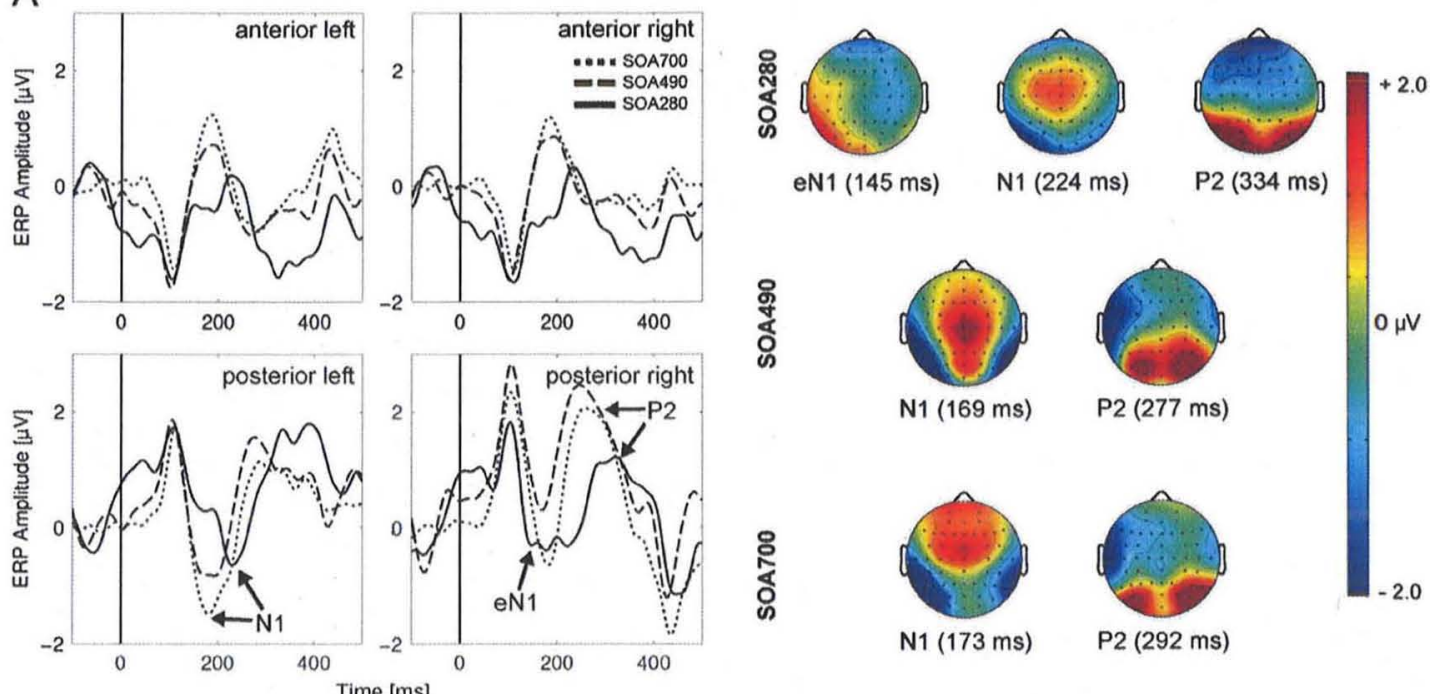

ㅇํㅀ
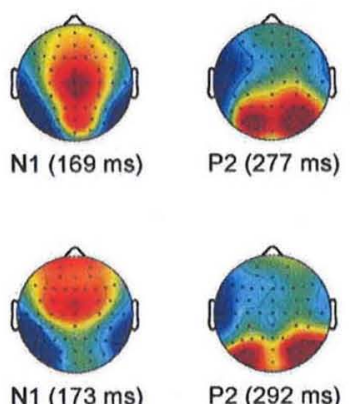

B
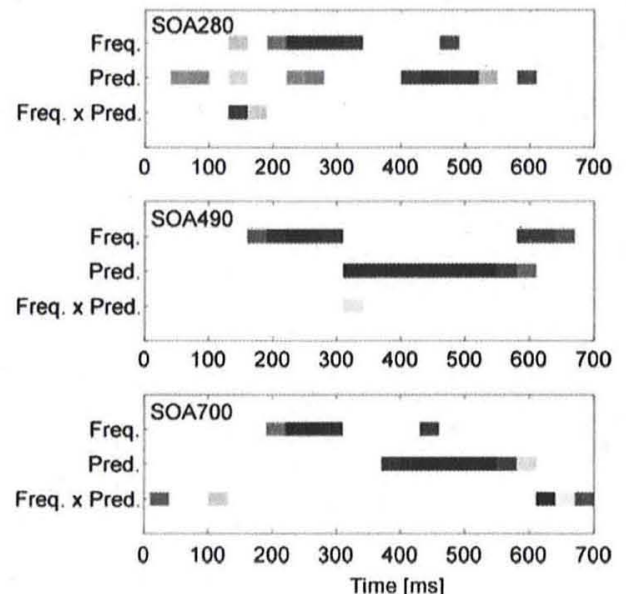

C
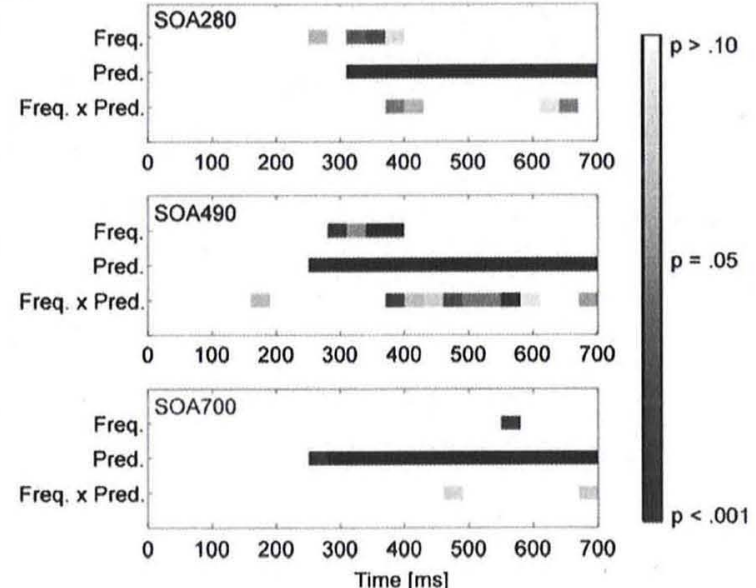

Fig. 8. Comparison between experiments. (A) Mean grand average ERPs aggregated across five left and right anterior (AF3/4, FP1/2, F1/2, F3/4, F5/6) and five left and right posterior channels (PO7/8, PO3/4, P5/6, P3/4, P1/2) in the three experiments with SOAs of 700, 490, and 280 ms. Topographies show scalp distributions of the absolute ERP waveforms at the eN1 (SOA of $280 \mathrm{~ms}$ only), N1, and P2 peak latencies. (B) and (C) Uncorrected p-values of ANOVAs in successive 30 ms intervals with frequency and predictability as factors for averaged channels $\mathrm{PO} / 8$ (panel B) and for channel $\mathrm{Pz}$ (panel C).

the $\mathrm{N} 1$ peaked at about $230 \mathrm{~ms}$, i.e., $50 \mathrm{~ms}$ later than in Experiments 1 and 2 . Third, the P2 reached its maximum after approximately $330 \mathrm{~ms}$, which is again around $50 \mathrm{~ms}$ later than in the previous experiments. Finally, an N400 emerged as a broad negative component.

\subsection{1. eN1}

From 135 to $155 \mathrm{~ms}$, main effects of frequency $[F(3,99)=.864$; $p=.469]$ and predictability $[F(3,110)=2.113 ; p=.092]$ were not significant in the global ANOVA; there was a weak statistical trend for predictability. However, the interaction of frequency and predictability was reliable $[F(3,119)=2.513 ; p=.047]$. Separate post-hoc ANOVAs on all electrodes within predictability categories revealed a significant frequency effect for high predictability $[F(3,106)=2.762 ; p=.039]$ but not for low predictability words $[F(3,111)=.593 ; p=.651]$. Similar to the frequency effects in Experiments 1 and 2, the scalp distribution within the high predictability category was negative over posterior and positive over anterior channels (Fig. 7(A)). Post-hoc ANOVAs on averaged electrodes PO7/8 confirmed the interaction of frequency and predictability $[F(1,31)=9.035 ; p=.005]$ with more negative amplitudes for low than for high frequency words in the high $[F(1,31)=11.908 ; p<.001]$ but not in the low predictability condition $[F(1,31)=1.057 ; p=.312]$.

4.2.2. N1. From 190 to $260 \mathrm{~ms}$, the main effect of predictability $[F(4$, $133)=1.584 ; p=.178]$ and the interaction of frequency and predictability $[F(3,102)=.681 ; p=.580]$ were not significant in the global ANOVA. A reliable effect of frequency $[F(2,86)=2.857$; $p=.046]$ showed more negative amplitudes for low than for high frequency words on posterior channels (Fig. 7(A) and (B)). The posthoc comparison on averaged electrodes $\mathrm{PO} / \mathrm{8}$ was significant $[F(1$, 31) $=13.521 ; p<001]$.

4.2.3. $P 2$. Main effects of frequency $[F(3,111)=3.641 ; p=.010]$ and predictability $[F(5,167)=10.011 ; p<.001]$ were significant in the global ANOVA from 300 to $360 \mathrm{~ms}$. The interaction of 
frequency and predictability was not reliable $(F<1)$. The frequency effect revealed more positive amplitudes for high than for low frequency words on posterior sites; an analysis on averaged channels PO7/8 confirmed this pattern $[F(1,31)=6.448$; $p=.012]$. Similar to the N1 effect, amplitude differences were negative at posterior and positive at anterior channels (Fig. 7(A) and (B)).

The predictability effect was distributed over centro-parietal channels with more negative amplitudes for low than for high predictability words (Fig. 7(C)). A post-hoc test on channel Pz was significant $[F(1,31)=16.169 ; p<.001]$. As this time interval falls into the $\mathrm{N} 400$ epoch, the result indicates an early phase of the N400 predictability effect.

4.2.4. N400. As in Experiments 1 and 2, predictability $[F(4$ $134)=36.320 ; p<.001]$ had a strong effect from 300 to $500 \mathrm{~ms}$, whereas frequency $[F(3,99)=1.743 ; p=.159]$ and the frequency $\times$ predictability interaction $[F(3,96)=.450 ; p=.726]$ were not reliable. Amplitudes were more negative for low than for high predictability words on centro-parietal channels (Fig. 7(C)). The posthoc comparison on electrode $\mathrm{Pz}$ was highly significant $[F(1$, $31)=106.491 ; p<.001]$.

\subsection{Discussion}

Using an SOA of $280 \mathrm{~ms}$, Experiment 3 assessed the time course of frequency and predictability effects under a nearnormal reading rate. Notably, compared to the longer SOAs in Experiments 1 and 2, the higher presentation rate yielded differences in the ERP morphology: While the P1 peaked at comparable latencies across all experiments, the N1 and P2 appeared to be shifted towards longer latencies in Experiment 3 . Further, the ERP course in Experiment 3 revealed an additional deflection at around $145 \mathrm{~ms}$ (eN1) that evolved into a plateau at posterior left and at anterior sites (Fig. 8(A)). We will further address the altered ERP morphology in the next section (5. Comparison between experiments).

Analyses in the eN1 interval revealed an interaction of frequency and predictability. Compatible with the idea that high expectancy of words can support early lexical processing, the interaction translated into a frequency effect only for high but not for low predictability words. The interaction, though, was relatively weak in the global analyses and occurred only in a brief interval on a deflection that was absent in Experiments 1 and 2 . Yet, there are reasons to take this finding serious: First, it is well known that effects in early time ranges are generally small and focal, so that rather mild amplitude modulations are expected (Penolazzi et al., 2007; Pulvermüller, Shtyrov, \& Hauk, 2009). Second, the effect is only weak in a conservative analysis including all channels, whereas post-hoc tests on averaged channels $\mathrm{PO} 7 / 8$ revealed a very robust pattern. Here, the interaction was significant for the much wider interval from 130 to $180 \mathrm{~ms}^{1}$ (see also Fig. 8(B)), i.e., the time range where Sereno et al. (2003) also found interactions between frequency and context. Third, and as a related issue, modulations on the posterior channels PO7/8 were predicted considering sizeable frequency effects on these electrodes in Experiments 1 and 2, as well as posterior distributions in

An ANOVA on averaged channels PO7/8 in the interval from 130 to $180 \mathrm{~ms}$ revealed a significant interaction of frequency $x$ predictability $[F(1,31)=6.813$ $p=.014]$. Post-hoc analyses within predictability categories yielded a frequency effect for high $[F(1,31)=7.796 ; p=.009]$ but not for low predictability words $[F(1$ $31)=1.220 ; p=278$ ]. In a global ANOVA on all electrodes in this interval, the interaction of frequency and predictability was marginally significant $[F(3,113)=$ $2.272 ; p=.058]$ with a trend for the frequency effect of high $[F(3,95)=$ $2.201 ; p=.091]$ but not of low predictability words $[F(4,124)=.966 ; p=.429]$. other studies investigating early frequency effects (e.g., Dimigen, Dambacher, Sommer, Kliegl, Jacobs, \& Hauk, 2011; Sereno et al., 1998). Accordingly, the topography of the frequency effect for high predictability words in Experiment 3 lines up with those from other reports (i.e., negative polarity over posterior sites). ${ }^{2}$ Hence, our results provide some evidence for a crosstalk between top-down expectancy and bottom-up input at early stages, suggesting that limited processing time at a fast reading rate encouraged the use of contextual information for word recognition; a replication, of course, would even strengthen this conclusion.

The interactive pattern of frequency and predictability was followed by a main effect of frequency on the N1 and P2 component. Similar to Experiments 1 and 2, ERP amplitudes were more negative for low than for high frequency words on posterior channels. The scalp distribution, though, suggested that the effect was larger for high than for low predictability words, presumably as a consequence of the interaction in the previous interval.

In addition to the frequency effect, P2 amplitudes were modulated by predictability. This is not surprising, considering that the P2 window (i.e., $300-360 \mathrm{~ms}$ ) temporally overlapped with the N400 epoch (i.e., 300-500 ms), which revealed a strong main effect of predictability on posterior channels. In line with the results of Experiments 1 and 2, neither the P2 nor the N400 revealed any further interaction of frequency and predictability (cf., Discussion of Experiment 1).

\section{Comparison between experiments}

In order to scrutinize effects of SOA on the ERP course, we compared the data from the three experiments in additional analyses. As pointed out above, visual inspection suggested that acceleration to a near-normal presentation rate affected the ERP morphology. While long SOAs of Experiments 1 and 2 produced rather similar ERP courses, the posterior N1 and P2 peaked around $50 \mathrm{~ms}$ later at the highest rate. Here, ERPs revealed a plateau starting after around $145 \mathrm{~ms}$ on anterior and left posterior sites such that subsequent components appeared to be temporally shifted (Fig. 8(A)). As a statistical test of SOA effects on $\mathrm{N} 1$ and $\mathrm{P} 2$ peaks, we conducted latency analyses on averaged channels PO7/8. In a jackknifing procedure, $n$ grand averages were computed from individual subject ERPs, with $n$ corresponding to the number of subjects. In this procedure, data of one subject $i$ $(i=1, \ldots, n)$ are omitted for each average (Miller, Patterson, \& Ulrich, 1998). Peak latencies were then detected for every jackknife average and submitted to pairwise ANOVAs with the between-subject factor SOA ( 280 vs. 490,280 vs. 700 , and 490 vs. 700); the resulting $F$-values were appropriately corrected for the reduction of error variances (Ulrich \& Miller, 2001).

Mean peak latencies of the $\mathrm{N} 1$ component were detected at 224,169 and $173 \mathrm{~ms}$ for the SOAs of 280,490 , and $700 \mathrm{~ms}$, respectively. The ANOVA confirmed that the $\mathrm{N} 1$ peaked significantly later with an SOA of 280 than of $490 \mathrm{~ms}[F(1,62)=51.767$; $p<.01]$ or of $700 \mathrm{~ms}[F(1,61)=10.833 ; p<.01]$. Peak latencies of the latter two SOAs did not differ $(F<1)$. Likewise, the P2 with

${ }^{2}$ Visual inspection of ERPs on channels PO7 and PO8 suggests that the negative polarity of the frequency effect in the high predictability condition predominantly resulted from more negative amplitudes for low frequency words, whereas ERPs to the other conditions hardly differed. Note, however, that this comparison of absolute amplitudes in Experiment 3 is rather inconclusive because the data revealed an early main effect of predictability in the interval from 50 to $90 \mathrm{~ms}$ (see Dambacher et al., 2009). Thus, ERPs to high and low predictability words differed from a very early point on, so that the temporal propagation of these differences, presumably involving differential processing, limits the validity of comparisons between predictability categories. 
latencies of 334,277 and $292 \mathrm{~ms}$ for the SOAs of 280,490 , and $700 \mathrm{~ms}$, respectively, peaked later with an SOA of $280 \mathrm{~ms}$ than of $490 \mathrm{~ms}[F(1,62)=6.954 ; p=.01]$ or of $700 \mathrm{~ms}[F(1,61)=44.192$; $p<.01$ ]; again, the latencies of the two longest SOAs did not differ $(F<1)$. A likely source for the distinct morphologies is specific ERP overlap patterns for different presentation rates. In particular, with a short SOA, components to previous and successive stimuli (e.g., visually evoked potentials) overlap temporally and add up with potentials evoked by the current word. In contrast, at a long SOA, the next stimulus occurs only after the period that is used for EEG averaging, so that its deflections do not interfere with the ERP to the current word. Hence, differential superposition of neural responses to consecutive stimuli at shorter compared to longer SOAs presumably contributed to modifications of the ERP. Yet, we cannot rule out that the distinct course at the SOA of $280 \mathrm{~ms}$ partly reflects temporal differences in lexical processing. ${ }^{3}$

In fact, there was also evidence for a modulated timeline of lexical processing with the high presentation rate. In Experiments 1 and 2, reliable main effects of frequency were observed on P2 amplitudes from 240 to $300 \mathrm{~ms}$. With an SOA of $490 \mathrm{~ms}$ (Exp. 2), though, $\mathrm{N} 1$ amplitudes revealed a trend in the global analyses and a significant frequency effect on posterior channels, pointing to an earlier onset than at the slowest SOA of $700 \mathrm{~ms}$ (Exp. 1). The earliest effect of frequency with an SOA of $280 \mathrm{~ms}$ (Exp. 3) occurred in an interaction with predictability on a deflection from 135 to $155 \mathrm{~ms}$, where only high predictability words revealed differences. The time course of these effects is displayed in Fig. 8(B) that shows uncorrected $p$-values of ANOVAs with the factors frequency and predictability in successive $30 \mathrm{~ms}$ intervals on averaged channels PO7/8, where all experiments revealed robust frequency effects. The plot suggests that between 100 and $250 \mathrm{~ms}$ post-stimulus, frequency-based effects occurred earlier as SOA decreased. ${ }^{4}$ To scrutinize the timeline of lexical processing, we determined the onset of frequency effects by means of jackknifed averages (see above; Miller et al., 1998; Ulrich \& Miller, 2001) on averaged channels PO7/8; for Experiment 3 , only the high predictability category was considered. Onset latencies were determined as the first of at least eleven successive samples (i.e., time windows longer than $20 \mathrm{~ms}$ ) revealing significant differences between ERPs to low and high frequency words. For the SOAs of 280,490 , and $700 \mathrm{~ms}$, frequency effects yielded latencies of 131, 174, and $207 \mathrm{~ms}$, respectively. Thus, the frequency effect started around $30 \mathrm{~ms}$ earlier in the medium compared to the longest SOA. This difference was

${ }^{3}$ On a similar note, absolute ERP amplitudes showed an asymmetry between left and right posterior channels. In Experiments 1 and 2, amplitudes on PO8 compared to PO7 were more positive in the time ranges of the N1, and P2 component (all $p$ 's $<.01$ ), and they were more negative in the N400 interval ( $p$ 's $<.03$ ), in accordance with patterns previously described for ERPs in sentence reading (Kutas \& King, 1996; Kutas, Van Petten, \& Besson, 1988). In Experiment 3. the asymmetry was only reliable in N1 and N400 intervals ( $p$ 's $<.01$ ). It is unclear whether the less pronounced asymmetry at the shortest SOA results from differential component overlap (especially considering that N1 and P2 latencies differed between experiments) or is, to some extent, related to stimulus processing at a high reading rate.

${ }^{4}$ Two other observations in Fig. 8B seem noteworthy: First, with an SOA of $280 \mathrm{~ms}$, a main effect of predictability started already before $100 \mathrm{~ms}$ after stimulus onset. This result is described in 6. General Discussion and is addressed elsewhere in more detail (Dambacher et al., 2009). Second, an interaction of frequency and predictability was observed shortly after stimulus onset under an SOA of $700 \mathrm{~ms}(p=.04)$. Considering the latency of less than $50 \mathrm{~ms}$, this effect is unlikely to result from visual processing of the target word. Also target-preceding words can be precluded as source as they were identical across conditions. One possibility, though, is that the effect mirrors top-down processes related to the prior context sentence. Alternatively, it may simply reflect an alpha error. This early difference in the time course, though, makes it difficult to interpret the brief interval at $120 \mathrm{~ms}$ where the frequency $\times$ predictability interaction revealed a statistical trend $(p=.08)$ significant in an ANOVA with SOA $(700,490)$ as between-subject factor $[F(1,61)=5.675 ; p=.02]$. Further, with an SOA of $280 \mathrm{~ms}$, the frequency effect for high predictability words occurred around $40 \mathrm{~ms}$ earlier than the frequency effect under an SOA of $490 \mathrm{~ms}[F(1,62)=7.017 ; p=.01]$. Compared to the SOA of $700 \mathrm{~ms}$, the latency difference of nearly $80 \mathrm{~ms}$ was even larger $[F(1$, $61)=39.417 ; p<.01]$. Hence, in accordance with the idea of accelerated lexical processing at higher input rates, onset times of frequency effects gradually decreased with SOA.

Analogously, we examined effects of SOA on the onset of N400 predictability effects. ANOVAs in successive $30 \mathrm{~ms}$ time windows suggested a later start with an SOA of 280 than of 490 or of $700 \mathrm{~ms}$ on channel Pz (Fig. 8(C)). Accordingly, jackknife-based onset latencies on successive data points amounted to 313,263, and $263 \mathrm{~ms}$ for the SOAs of 280,490 , and $700 \mathrm{~ms}$, respectively. The difference was significant between the SOAs of 280 and $700 \mathrm{~ms}$ [F(1, $61)=4.224 ; p=.04]$, whereas, the $50 \mathrm{~ms}$ delay between the SOA of 280 and $490 \mathrm{~ms}$ was not reliable $[F(1,61)=1.863 ; p=.18]$. The latter result points to a larger variance of onset latencies at the medium presentation rate.

Finally, we examined N400 amplitude effects between the experiments. For a statistical comparison, N400 difference waves (low minus high predictability) on channel $\mathrm{Pz}$ were computed for each SOA. Mean amplitudes in the interval from 300 to 500 amounted to $-1.52,-2.47$, and $-2.05 \mu \mathrm{V}$ for the SOAs of 280 , 490 , and $700 \mathrm{~ms}$, respectively. Individual subject data were submitted to pairwise ANOVAs with SOA ( 280 vs. 490,280 vs. 700 , and 490 vs. 700 ) as between-subject factors. The results revealed a smaller predictability effect at the SOA of $280 \mathrm{~ms}$ compared to the SOA of $490 \mathrm{~ms}[F(1,62)=9.686 ; p<.01]$ as well as compared to the SOA of $700 \mathrm{~ms}[F(1,61)=5.357 ; p=.02]$. Differences between the two long SOAs were not significant $[F(1$, $61)=1.675 ; p=.20]$.

\section{General discussion}

ERPs provide important and temporally accurate information about processes of visual word recognition. Methodological constraints, though, limit the investigation of more natural reading situations: Words are usually presented one at a time at stimulus onset asynchronies (SOAs) that are considerably slower than the rate of normal reading. Surprisingly, SOA effects are not well established in psycholinguistic research, so that it is unknown whether results from rather artificial settings translate one to one to natural reading. The present study therefore tested effects of presentation rate on the ERP course of word recognition, and specifically on the timeline of bottom-up stimulus processing and top-down expectations in reading. In three experiments, word frequency and predictability were manipulated on target words that were embedded in otherwise identical sentences. Words were presented with SOAs of 700 and $490 \mathrm{~ms}$ in Experiments 1 and 2, respectively, corresponding to the range of display rates commonly used in psycholinguistic ERP studies. In addition, we employed a near-normal presentation rate of $280 \mathrm{~ms}$ per word in Experiment 3. In the following, we discuss the time course of frequency and predictability effects together with similarities and differences between the SOA conditions.

First, all experiments revealed the earliest frequency effect within $210 \mathrm{~ms}$ after stimulus onset. Critically, the scalp topographies were similar across all experiments and showed up as negative amplitude differences over posterior sites; the remarkable consistency of this pattern strengthens the validity of the present results and informs about the distribution of early frequency effects, which have often been considered as an index for advanced lexical processing. Accordingly, the data are in line 
with previous reports of frequency effects within the first $200 \mathrm{~ms}$, indicating that word recognition relies on the rapid processing of the visual word form (Braun et al., 2009; Dambacher et al., 2006; Hauk et al., 2006; Hauk \& Pulvermüller, 2004; Penolazzi et al., 2007; Sereno et al., 1998, 2003). Yet, the results also extend existing evidence since they revealed differences between experiments: The latency of frequency effects gradually decreased with the presentation rate of words. With an SOA of $700 \mathrm{~ms}$ in Experiment 1, the frequency effect started at $207 \mathrm{~ms}$ on the P2. Experiment 2 (SOA of $490 \mathrm{~ms}$ ) revealed an onset after $174 \mathrm{~ms}$ on the $\mathrm{N} 1$ component, and Experiment 3 (SOA of $280 \mathrm{~ms}$ ) disclosed the first effect of frequency for high predictability words after $131 \mathrm{~ms}$ on an early deflection (eN1). The data therefore suggest that time constraints imposed by a higher presentation rate accelerate word recognition. Optimal performance may be achieved under (near)-normal conditions that limit the time for word processing. Hence, this result contributes to the link between the timelines of word recognition from ERPs and from eye movements during natural reading (cf., Kliegl, Dambacher, Dimigen, Jacobs, \& Sommer, 2012).

The idea of accelerated processing at a high reading rate was supported by a second difference between the experiments. With the long SOAs of Experiments 1 and 2, frequency and predictability did not significantly interact in common intervals (i.e., there was evidence only for additive effects of frequency and predictability). Thus, if we accept the null result for the interaction, the findings are compatible with the speculation of independent processing of bottom-up and top-down information (cf., Penolazzi et al., 2007). The near-normal presentation rate in Experiment 3, however, revealed an interaction of frequency and predictability within the first $200 \mathrm{~ms}$ : Frequency effects were observed in the high but not in the low predictability condition, suggesting that expectancy-driven information supports early lexical processes. The finding lines up with other reports of early availability of context-based information. In ERPs, words evoke increased brain-electrical responses, when their forms mismatch those of expected upcoming stimuli (DeLong et al., 2005; Van Berkum et al., 2005; Wicha et al., 2003, 2004). In eye movements, biasing contexts prompt anticipatory saccades to objects representing likely continuations of stories (Altmann \& Kamide, 1999, 2007; Kamide et al., 2003; Kamide et al., 2003). Moreover, in natural reading, highly predictable words are fixated shorter and are skipped more often than low predictable words; apparently, a supporting context facilitates word processing within one fixation duration (usually less than $250 \mathrm{~ms}$ ), or even renders inspections of high predictability stimuli dispensable (Ashby et al., 2005; Ehrlich \& Rayner, 1981; Kliegl et al., 2004, 2006; Rayner et al. 2004). Accordingly, the present results provide converging evidence that expectancy of upcoming words can rapidly affect natural word processing.

The rapid involvement of top-down information under a nearnormal reading rate was substantiated by another observation in Experiment 3 that has been reported elsewhere (Dambacher Rolfs, Göllner, Kliegl, \& Jacobs, 2009). From 50 to $90 \mathrm{~ms}$, ERPs over posterior sites revealed a very early effect of predictability (cf., Fig. 8(B)). We proposed that the effect reflects rapid verification of pre-activated mental representations of expected words with the actual physical input; that is, shortly after the visual signal reaches the cortex, neural activity differentiates predictions matching the incoming visual signal from those producing a mismatch (cf., DeLong et al., 2005; Gilbert \& Sigman, 2007; Grossberg, 1999; Mumford, 1992; Ullman, 1995; Van Berkum et al., 2005; Wicha et al., 2003, 2004). Similarly, in sentences presented at normal speaking rates (i.e., around 120 to 200 words per minute; cf., Rayner \& Clifton, 2009), ERPs to predicted and unpredicted adjective inflections differed no later than $50 \mathrm{~ms}$ after inflection onset (Van Berkum et al., 2005). Together, these findings support the notion that early processes are primarily engaged when perceptual load and task requirements are high (Handy \& Mangun, 2000; Lavie, 1995, 2005; Lavie \& Tsal, 1994; Luck, Woodman, \& Vogel, 2000).

As a third major finding, robust N400 effects were observed in all experiments. In agreement with numerous previous studies, N400 amplitudes were larger for low than for high predictability words, and the effects yielded very similar topographies across SOAs (Kutas \& Federmeier, 2011; Kutas \& Van Petten, 1994; Kutas et al., 2006). In addition, the results consistently showed no effect of word frequency on $\mathrm{N} 400$ amplitudes, neither as a main effect nor in interaction with predictability. While this differs from reports of an interplay between frequency and predictability, the absence of frequency-based N400 modulations in the present study can presumably be ascribed to high contextual constraints in our stimuli (Van Petten \& Kutas, 1990; cf., Discussion of Experiment 1). The stability of this pattern across SOAs suggests that, independent of presentation rate, $\mathrm{N} 400$ amplitudes are more susceptible to contextual information than to stimulus form, when prior sentence fragments strongly bias the expectation of one (or a few) words.

Apart from these consistencies, there was also evidence that the N400 is sensitive to display rate. Earlier comparisons of a very short SOA of $100 \mathrm{~ms}$ with a long SOA of $700 \mathrm{~ms}$ during sentence reading revealed longer peak (Kutas, 1987) and onset (Robichon et al., 2002) latencies of N400 effects on sentence-final words for the short SOA; no amplitude differences were reported in these experiments. Longer onset latencies as well as smaller N400 amplitudes for an SOA of 200 compared to $1000 \mathrm{~ms}$ were found in a semantic priming study (Rossell et al., 2003). The present data extend these findings as they provide a comparison of three graded SOA levels in sentence reading, involving a near-normal rather than a very high rate of $100 \mathrm{~ms}$. Results show a later onset and smaller amplitude of the N400 predictability effect for the SOA of $280 \mathrm{~ms}$ compared to the longer SOAs. Thus, N400 effects seem to be delayed especially when the display rate is high, whereas there were no differences between a medium (490 ms) and a long (700 ms) SOA.

In contrast to the pattern of accelerated processing earlier in the time course, N400 results therefore point to delayed and attenuated effects under high reading rates. A possible reason is that at the short SOA the N400 coincided with the presentation of the next word. That is, ongoing neural activity to a target word temporally overlapped with the display of the subsequent stimulus. Consequently, two words were presumably processed simultaneously, a situation that may absorb and decelerate N400-related mechanisms. In fact, evidence for concurrent processing revealed a crosstalk between consecutive words during normal reading, in that N400 amplitudes were predictive for fixation durations on the subsequent word (Dambacher \& Kliegl, 2007). As another potential contributor, high presentation rates grant only limited time to build up expectations about the upcoming word. Hence, a smaller degree of semantic preactivation may result in a reduced difference of predictable and unpredictable words (e.g., Federmeier \& Kutas, 1999; Lau et al., 2008). Yet, the results of Experiment 3 also point to the availability and the use of contextual information prior to the N400. Given that with an SOA of $280 \mathrm{~ms}$ context information was presumably involved in early lexical processing, the smaller N400 effect may also reflect facilitated semantic integration. As it stands, the exact nature of N400 modulations is not fully understood, but the pattern of early and late effects in the ERP course indicates that visually-driven bottom-up processing and context-driven top-down expectations take place on several levels and time-scales (cf., Kutas, 2006; Kutas \& Federmeier, 2011). 
As a fourth observation, ERP morphologies were modulated by presentation rate (Fig. 8(A)). Particularly the SOA of $280 \mathrm{~ms}$ revealed a shifted time course, with peak latencies of the posterior $\mathrm{N} 1$ and $\mathrm{P} 2$ components occurring approximately 50 ms later compared to SOAs of 490 or $700 \mathrm{~ms}$; the two latter conditions did not differ. Further, the fastest SOA yielded a short-living deflection at around $145 \mathrm{~ms}$ that evolved into a plateau and that was absent at the longer SOAs. A likely reason for the modified morphology is the different degree of ERP overlap at different reading speeds (cf. Dimigen et al., 2011). At low presentation rates, neural responses to successive words interfere late in the time course, so that ERPs are largely affected only by a currently presented target word. In contrast, high presentation rates lead to a temporal overlap of the brain-electric fields evoked by the preand post-target words with those evoked by the target. This summation of ERP components alters the wave shape, such that also absolute amplitude maxima can be shifted. Yet, considering that an SOA of $280 \mathrm{~ms}$ presumably involves - at least partly parallel processing of consecutive words (Dambacher \& Kliegl, 2007; Kliegl et al., 2012), it is also possible that the eN1 deflection and the subsequent delay of components was co-determined by specific lexical processes at a near-normal reading rate. While the exact meanings of constituents in the altered ERP morphology remain subject to future research, the observation that especially the ERPs at the fastest display rate differ from those at slower SOAs lines up with the evidence for a particular role of a natural reading rate.

Together, the present findings support two conclusions. First, the data provide some evidence for accelerated processing and for an interaction of frequency and predictability at a fast reading rate. This is relevant for models of word recognition, as it implies the consideration of rapid and joint effects of word- and contextbased information in normal reading. In general, models belonging to the interactive activation family are compatible with this demand as they permit a simultaneous processing of bottom-up and top-down signals. Yet, they have been mostly optimized for recognition of isolated words and are in need of further specification for performance on a sentence level (e.g., Grainger \& Jacobs, 1996; Jacobs et al., 1998; McClelland \& Rumelhart, 1981; Rumelhart \& McClelland, 1982). Providing temporal conditions and constraints, our results may contribute to the advancement of theoretical accounts, and hence to a cross-fertilization between cognitive models and neuroscience (Braun, Jacobs, Hahne, Ricker, Hofmann, \& Hutzler, 2006; Barber \& Kutas, 2007; Grainger \& Holcomb, 2008, 2009; Jacobs \& Carr, 1995)

Second, while some effects were rather similar across SOAs, the results also demonstrate that the time course of word recognition is modulated by the rate at which words are presented. This seems particularly critical for the precise tracking of the chronology of effects under normal reading rate; results obtained with unnaturally long SOAs do not necessarily translate one to one to fast reading. Employing near-normal presentation rates, of course, is not without problems either. ERPs to successive words temporally overlap at a high presentation rate such that neural responses to several stimuli superimpose each other. The interpretation of results on critical words is therefore difficult as effects may be confounded with the processing of preceding or succeeding words. This, however, is only problematic when neighboring words differ between experimental conditions. The present study circumvented this problem by using sentence frames that were identical across all conditions. Thus, one solution can be the use of stimuli that permit inferences despite component overlap.

Certainly, even with a normal presentation rate, the RSVP procedure remains artificial and can only approximate natural reading where subjects move their eyes freely across sentences at their own pace (cf., Ditman et al., 2007; Nieuwland \& Van Berkum, 2006). The serial presentation of words at screen center severely constrains reading dynamics and may therefore affect word recognition processes as well. Future research has to show if and under what conditions artificial experimental settings mirror or distort natural reading processes. A very promising technique in this respect is the simultaneous recording of EEG and eye movements that combines the high temporal resolution of electrophysiological recordings with ecologically valid reading situations. In fact, recent results demonstrate that methodological and theoretical problems can be mastered (Dimigen et al., 2011; see also Baccino \& Manunta, 2005; Dimigen et al., 2009; Dimigen, Kliegl, \& Sommer, in press; Hutzler et al., 2007; Kretzschmar, Bornkessel-Schlesewsky, \& Schlesewsky, 2009; Kliegl et al., 2012; Simola, Holmqvist, \& Lindgren, 2009). There is reason to believe that this technique has the potential to provide novel insights not only into the timeline of word recognition but into visual perception in general.

\section{Conclusions}

Three ERP experiments showed similarities and differences in the timeline of word recognition across three SOAs. In general, we replicated well-established effects of frequency and predictability on different ERP components for all SOAs. The most prominent differences relate to the relative timelines of frequency and predictability effects: First, the latency of early word frequency effects decreased gradually with SOA. Second, only a near-normal presentation rate yielded a reliable interaction of top-down and bottom-up processing. Third, the N400 predictability effect was delayed and smaller at a near-normal compared to lower presentation rates. Fourth, the ERP morphology revealed differences at the shortest compared to the two longer SOAs. In summary, the findings point to a special role of a near-normal presentation rate for the timeline of word recognition, and thus suggest consideration of SOA in research on natural reading.

\section{Funding}

This research was supported by Deutsche Forschungsgemeinschaft, grants FOR868/1 and KL655/6-1. The first author was also supported by the Zukunftskolleg of the Universität Konstanz, Germany. The funders had no role in study design, data collection and analysis, decision to publish, or preparation of the manuscript.

\section{Conflict of interest}

The authors declare that no competing interests exist.

\section{Acknowledgments}

We thank Ralf Engbert, Markus Hofmann, Lars Kuchinke, Konstantin Mergenthaler, Antje Nuthmann, Martin Rolfs, Werner Sommer, Sascha Tamm, Hans Trukenbrod, Christiane Wotschack, and Kay-Michael Würzner for their support and valuable comments. Experiments 1 and 3 were carried out as part of the first author's dissertation (Dambacher, 2010). Parts of the data of Experiment 3 were reported in Dambacher et al. (2009). Address for correspondence: Michael Dambacher, Department of Psychology, University of Konstanz, 78457 Konstanz, Germany, e-mail: michael.dambacher@uni-konstanz.de. 


\section{References}

Altmann, G. T. M. (1997). The Ascent of Babel. An Exploration of Language, Mind, and Understanding. Oxford: Oxford University Press.

Altmann, G. T. M., \& Kamide, Y. (1999). Incremental interpretation at verbs: restricting the domain of subsequent reference. Cognition, 73(3), 247-264

Altmann, G. T. M., \& Kamide, Y. (2007). The real-time mediation of visual attention by language and world knowledge: linking anticipatory (and other) eye movements to linguistic processing. Journal of Memory and Language, 57. 502-518.

Altmann, G. T. M., \& Mirkovic, J. (2009). Incrementality and prediction in human sentence processing. Cognitive Science, 33, 583-609.

Ashby, J., Rayner, K., \& Clifton, C. (2005). Eye movements of highly skilled and average readers: differential effects of frequency and predictability. Quarterly Journal of Experimental Psychology, 58(6), 1065-1086.

Baccino, T., \& Manunta, Y. (2005). Eye-fixation-related potentials: insight into parafoveal processing. Journal of Psychophysiology, 19(3), 204-215.

Bar, M. (2007). The proactive brain: using analogies and associations to generate predictions. Trends in Cognitive Sciences, 11(7), 280-289.

Barber, H. A., \& Kutas, M. (2007). Interplay between computational models and cognitive electrophysiology in visual word recognition. Brain Research Reviews, 53(1), 98-123.

Braun, M., Hutzler, F., Ziegler, J. C., Dambacher, M., \& Jacobs, A. M. (2009) Pseudohomophone effects provide evidence of early lexico-phonological processing in visual word recognition. Human Brain Mapping, 30, 1977-1989.

Braun, M., Jacobs, A. M., Hahne, A., Ricker, B. Hofmann, M., \& Hutzler, F. (2006) Model-generated lexical activity predicts graded ERP amplitudes in lexica decision. Brain Research, 1073, 431-439.

Brown, C. M., \& Hagoort, P. (1993). The processing nature of the N400: evidence from masked priming. Journal of Cognitive Neuroscience, 5(1), 34-44.

Brown, C. M., Hagoort, P.. \& ter Keurs, M. (1999). Electrophysiological signatures of visual lexical processing: open- and closed-class words. Journal of Cognitive Neuroscience, 11(3), 261-281.

Burgess, C., Tanenhaus, M. K., \& Seidenberg, M. S. (1989). Context and lexical access: implications of nonword interference for lexical ambiguity resolution. Journal of Experimental Psychology: Learning, Memory, and Cognition, 15(4), 620-632.

Calvo, M. G., \& Meseguer, E. (2002). Eye movements and processing stages in reading: relative contribution of visual, lexical, and contextual factors. The Spanish Journal of Psychology, 5(1), 66-77.

Camblin, C. C., Ledoux, K., Boudewyn, M., Gordon, P. C., \& Swaab, T. Y. (2007) Processing new and repeated names: effects of coreference on repetition priming with speech and fast RSVP. Brain Research, 1146, 172-184.

Carlsson, K., Petrovic, P., Skare, S., Petersson, K. M., \& Ingvar, M. (2000). Tickling expectations: neural processing in anticipation of a sensory stimulus. Journal of Cognitive Neuroscience, 12(4), 691-703.

Churchland, P. S., Ramachandran, V. S., \& Sejnowski, T. J. (1994). A critique of pure vision. In: C. Koch, \& J. L. Davis (Eds.), Large-scale Neuronal Theories of the Brain (pp. 23-60). Cambridge MA: MIT Press.

Corbetta, M., \& Shulman, G. L. (2002). Control of goal-directed and stimulus-driven attention in the brain. Nature Reviews Neuroscience, 3(3), 201-215.

Dambacher, M. (2010). Bottom-up and top-down processes in reading: influences of frequency and predictability on event-related potentials and eye movements. PhD Thesis, Potsdam: Universitätsverlag Potsdam.

Dambacher, M., \& Kliegl, R. (2007). Synchronizing timelines: relations between fixation durations and $\mathrm{N} 400$ amplitudes during sentence reading. Brain Research, 1155, 147-162.

Dambacher, M., Kliegl, R., Hofmann, M. \& Jacobs, A. M. (2006). Frequency and predictability effects on event-related potentials during reading. Brain Research, 1084, 89-103 Retrieved Apr, from Article database.

Dambacher, M., Rolfs, M., Göllner, K., Kliegl, R., \& Jacobs, A. M. (2009). Eventrelated potentials reveal rapid verification of predicted visual input. PLoS One 4(3), e5047.

Deacon, D., Dynowska, A., Ritter, W., \& Grose-Fifer, J. (2004). Repetition and semantic priming of nonwords: implications for theories of N400 and word recognition. Psychophysiology, 41(1), 60-74.

Deacon, D., Hewitt, S., Yang, C. M., \& Nagata, M. (2000). Event-related potential indices of semantic priming using masked and unmasked words: evidence that the N400 does not reflect a post-lexical process. Cognitive Brain Research. $9(2), 137-146$

DeLong, K. A., Urbach, T. P., \& Kutas, M. (2005). Probabilistic word pre-activation during language comprehension inferred from electrical brain activity. Nature Neuroscience, 8(8), 1117-1121.

DeLong, K. A., Urbach, T. P., Groppe, D. M., \& Kutas, M. (2011). Overlapping dual ERP responses to low cloze probability sentence continuations. Psychophysio$\log , 48,1203-1207$

Delorme, A., \& Makeig, S. (2004). EEGLAB: an open source toolbox for analysis of single-trial EEG dynamics including independent component analysis. Journal of Neuroscience Methods, 134(1), 9-21.

Dimigen, O., Dambacher, M., Sommer, W., Kliegl, R., Jacobs, A. M., \& Hauk, O. (2011). Early correlates of word recognition in fixation-related and eventrelated potentials: a comparison using simultaneous eye tracking and EEG. Journal of Cognitive Neuroscience, Supplement 104-104

Dimigen, O., Kliegl, R., \& Sommer, W. Trans-saccadic parafoveal preview benefits in fluent reading: a study with fixation-related brain potentials. Neuroimage, http://dx.doi.org/10.1016/j.neuroimage.2012.04.006, in press.
Dimigen, O., Sommer, W., Hohlfeld, A., Jacobs, A. M., \& Kliegl, R. (2011). Coregistration of eye movements and EEG in natural reading: analyses and review. Journal of Experimental Psychology: General, 140(4), 552-572.

Dimigen, O., Valsecchi, M., Sommer, W., \& Kliegl, R. (2009). Human microsaccaderelated visual brain responses. The Journal of Neuroscience, 29(39), 12321-12331

Ditman, T., Holcomb, P. J., \& Kuperberg, G. R. (2007). An investigation of concurrent ERP and self-paced reading methodologies. Psychopliysiology, 44, 927-935.

Duffy, S. A., Henderson, J. M., \& Morris, R. K. (1989). Semantic facilitation of lexical access during sentence processing. Journal of Experimental Psychology: Learn ing, Memory, and Cognition, 15(5), 791-801.

Ehrlich, S. F., \& Rayner, K. (1981). Contextual effects on word perception and eyemovements during reading. Journal of Verbal Learning and Verbal Behavior. $20(6), 641-655$.

Elman, J. L. (2004). An alternative view of the mental lexicon. Trends in Cognitive Sciences, 8(7), 301-306.

Engbert, R., Nuthmann, A., Richter, E. M., \& Kliegl, R. (2005). SWIFT: a dynamical model of saccade generation during reading. Psychological Review, 112(4), 777-813.

Engel, A. K., Fries, P., \& Singer, W. (2001). Dynamic predictions: oscillations and synchrony in top-down processing. Nature Reviews Neuroscience, 2(10), $704-716$

Enns, J. T., \& Lleras, A. (2008). What's next? New evidence for prediction in human vision. Trends in Cognitive Sciences, 12(9), 327-333.

Federmeier, K. D., \& Kutas, M. (1999). A rose by any other name: long-term memory structure and sentence processing. Journal of Memory and Language, $41,469-495$

Federmeier, K. D., Wlotko, E. W., De Ochoa-Dewald, E., \& Kutas, M. (2007). Multiple effects of sentential constraint on word processing. Brain Research, 1146, 75-84.

Fischler, I., \& Bloom, P. A. (1979). Automatic and attentional processes in the effects of sentence contexts on word recognition. Journal of Verbal Learning and Verbal Behavior, 18(1), 1-20.

Fodor, J. A. (1983). The Modularity of Mind. Cambridge, MA: MIT Press.

Forster, K. I. (1976). Accessing the mental lexicon. In: R. J. Wales, \& E. L. Walker (Eds.), New Approaches To Language Mechanisms: A Collection Of Psycholinguistic Studies (pp. 257-287). North Holland: Amsterdam.

Forster, K. I., \& Chambers, S. M. (1973). Lexical access and naming time. Journal of Verbal Learning and Verbal Behavior, 12(6), 627-635.

Geyken, A. (2007). The DWDS corpus: a reference corpus for the German language of the 20th century. In: C. Fellbaum (Ed.), Idioms and Collocations: Corpus-based Linguistic, Lexicographic Studies (pp. 23-40). London: Continuum Press.

Gilbert, C. D., \& Sigman, M. (2007). Brain states: top-down influences in sensory processing. Neuron, 54, 677-696.

Glucksberg, S., Kreuz, R. J., \& Rho, S. H. (1986). Context can constrain lexical access: implications for models of language comprehension. Journal of Experimental Psychology: Learning, Memory, and Cognition, 12(3), 323-335.

Grainger, J., \& Holcomb, P. J. (2008). Neural constraints on a functional architecture for word recognition. In: P. Cornelissen, P. Hansen, M. Kringelbach, \& K. Pugh (Eds.), The neural basis of reading. Oxford: Oxford University Press.

Grainger, J., \& Holcomb. P. J. (2009). Watching the word go by: on the time-course of component processes in visual word recognition. Language and Linguistics Compass, 3(1), 128-156.

Grainger, J. \& Jacobs, A. M. (1996). Orthographic processing in visual word recognition: a multiple read-out model. Psychological Review, 103(3), 518-565.

Grossberg, S. (1999). The link between brain learning, attention, and consciousness. Consciousness and Cognition, 8(1), 1-44.

Gunter, T. C.. Jackson, J. L., \& Mulder, G. (1992). An electrophysiological study of semantic processing in young and middle-aged academics. Psychophysiology, 29(1), 38-54.

Hagoort, P., Brown, C., \& Groothusen, J. (1993). The syntactic positive shift (SPS) as an ERP measure of syntactic processing. Language and Cognitive Processes, 8(4) 439-483.

Hagoort, P., \& Brown, C. M. (2000). ERP effects of listening to speech: semantic ERP effects. Neuropsychologia, 38(11), 1518-1530.

Handy, T. C., \& Mangun, G. R. (2000). Attention and spatial selection: electrophysiological evidence for modulation by perceptual load. Perception and Psychophysics, 62(1), 175-186.

Hauk, O., Davis, M. H., Ford, M., Pulvermüller, F., \& Marslen-Wilson, W. D. (2006) The time course of visual word recognition as revealed by linear regression analysis of ERP data. Neuroimage, 30(4), 1383-1400.

Hauk, O. \& Pulvermüller, F. (2004). Effects of word length and frequency on the human event-related potential. Clinical Neurophysiology, 115(5), 1090-1103.

Heister, J., Würzner, K.-M., Bubenzer, J., Pohl, E., Hanneforth, T., Geyken, A., et al (2011). dlexDB - eine lexikalische Datenbank für die psychologische und linguistische Forschung [dlexDB - a lexical data base for psychological and linguistic research]. Psychologische Rundschau, 62, 10-20.

Holcomb. P. J. (1993). Semantic priming and stimulus degradation: implication for the role of the N400 in language processing. Psychophysiology, 30(1) 47-61.

Holcomb, P. J., \& Neville, H. J. (1991). Natural speech perception: an analysis using event-related brain potentials. Psychobiology, 19(4), 288-300.

Hutzler, F., Braun, M., Vo, M. L. H., Engl, V., Hofmann, M., Dambacher, M., et al. (2007). Welcome to the real world: validating fixation-related brain potentials for ecologically valid settings. Brain Research, 1172, 124-129.

Inhoff, A. W. \& Rayner, K. (1986). Parafoveal word processing during eye fixations in reading: effects of word frequency. Perception and Psychophysics, 40(6). 431-439. 
Jacobs, A. M., \& Carr, T. H. (1995). Mind mappers and cognitive modelers: toward cross-fertilization. Behavioral and Brain Sciences, 18(2), 362-363.

Jacobs, A. M., Rey, A., Ziegler, J. C., \& Grainger, J. (1998). MROM-p: an interactive activation, multiple readout model of orthographic and phonological processes in visual word recognition. In: J. Grainger, \& A. M. Jacobs (Eds.), Localist Connectionist Approaches to Human Cognition (pp. 147-188). Mahwah, NJ: Lawrence Erlbaum Associates.

Kamide, Y., Altmann, G. T. M., \& Haywood, S. L. (2003). The time-course of prediction in incremental sentence processing: evidence from anticipatory eye movements. Journal of Memory and Language, 49(1), 133-156.

Kamide, Y., Scheepers, C., \& Altmann, G. T. M. (2003). Integration of syntactic and semantic information in predictive processing: cross-linguistic evidence from German and English. Journal of Psycholinguistic Research, 32(1), 37-55.

Kastner, S., Pinsk, M. A., De Weerd, P., Desimone, R., \& Ungerleider, L. G. (1999). Increased activity in human visual cortex during directed attention in the absence of visual stimulation. Neuron, 22(4), 751-761.

Kintsch, W., \& Mross, E. F. (1985). Context effects in word identification. Journal of Memory and Language, 24(3), 336-349.

Kleiman, G. M. (1980). Sentence frame contexts and lexical decisions: sentenceacceptability and word-relatedness effects. Memory and Cognition, 8(4) 336-344.

Kliegl, R., Dambacher, M., Dimigen, O., Jacobs, A. M., \& Sommer, W. (2012). Eye movements and brain electric potentials during reading. Psychological Research, 76(2), 145-158.

Kliegl, R., Grabner, E., Rolfs, M., \& Engbert, R. (2004). Length, frequency, and predictability effects of words on eye movements in reading. European Journal of Cognitive Psychology, 16(1-2), 262-284.

Kliegl, R., Nuthmann, A., \& Engbert, R. (2006). Tracking the mind during reading: the influence of past, present, and future words on fixation durations. Journal of Experimental Psychology: General, 135(1), 12-35.

Kotz, S. A., Von Cramon, D. Y., \& Friederici, A. D. (2005). On the role of phonological short-term memory in sentence processing: ERP single case evidence on modality-specific effects. Cognitive Neuropsychology, 22(8), 931-958.

Kretzschmar, F., Bornkessel-Schlesewsky, I., \& Schlesewsky, M. (2009). Parafoveal versus foveal N400s dissociate spreading activation from contextual fit. Neuroreport, 20(18), 1613-1618.

Kuperman, V., Dambacher, M., Nuthmann, A., \& Kliegl, R. (2010). The effect of word position on eye movements in sentence and paragraph reading. Quarterly Journal of Experimental Psychology, 63, 1838-1857.

Kutas, M. (1987). Event-related brain potentials (ERPs) elicited during rapid serial visual presentation of congruous and incongruous sentences. In: R. Johnson, R., Jr., J. W. Rohrbaugh, \& R. Parasuraman (Eds.), Current Trends in Event-Related Potentia Research, EEG Suppl. 40 (pp. 406-411). Elsevier Science Publishers B. V.

Kutas, M. (2006). One lesson learned: frame language processing - literal and figurative - as a human brain function. Metaphor and symbol, 21(4), 285-325.

Kutas, M., \& Federmeier, K. D. (2011). Thirty years and counting: finding meaning in the N400 component of the event-related brain potential (ERP). Annual Review of Psychology, 62(1), 621-647.

Kutas, M., \& Hillyard, S. A. (1980). Reading senseless sentences: brain potentials reflect semantic incongruity. Science, 207(4427), 203-205.

Kutas, M., \& King, J. W. (1996). The potentials for basic sentence processing: differentiating integrative processes. In: T. Inui, \& J. L. McClelland (Eds.) Attention and Performance XVI (pp. 501-546). Cambridge, MA: MIT Press.

Kutas, M., \& Van Petten, C. (1994). Psycholinguistics electrified: event-related brain potential investigations. In: M. A. Gernsbacher (Ed.), Handbook of Psycholinguistics (pp. 83-143). San Diego: Academic Press.

Kutas, M., Van Petten, C., \& Besson, M. (1988). Event-related potential asymmetries during the reading of sentences. Electroencephalography and Clinical Neurophysiology, 69, 218-233.

Kutas, M., Van Petten, C., \& Kluender, R. (2006). Psycholinguistics electrified II: 1994-2005. In: M. A. Gernsbacher, \& M. Traxler (Eds.), Handbook of Psycholinguistics (2nd edn.). New York: Elsevier Press.

Kveraga, K., Ghuman, A. S., \& Bar, M. (2007). Top-down predictions in the cognitive brain. Brain and Cognition, 65, 145-168.

Lau, E. F., Phillips, C., \& Poeppel, D. (2008). A cortical network for semantics: (de)constructing the N400. Nature Reviews Neuroscience, 9, 920-933.

Lavie, N. (1995). Perceptual load as a necessary condition for selective attention. Journal of Experimental Psychology: Human Perception and Performance, 21(3), $451-468$

Lavie, N. (2005). Distracted and confused? Selective attention under load. Trends in Cognitive Sciences, 9(2), 75-82.

Lavie, N., \& Tsal, Y. (1994). Perceptual load as a major determinant of the locus of selection in visual attention. Perception and Psychophysics, 56(2), 183-197.

Ledoux, K., Gordon, P. C., Camblin, C. C., \& Swaab, T. Y. (2007). Coreference and lexical repetition: mechanisms of discourse integration. Memory and Cognition, 35(4), 801-815.

Lucas, M. M. (1987). Frequency effects on the processing of ambiguous words in sentence contexts, Language and Speech, 30, 25-46.

Luck, S. J., Woodman, G. F., \& Vogel, E. K. (2000). Event-related potential studies of attention. Trends in Cognitive Sciences, $4(11), 432-440$

McClelland, J. L., \& Rumelhart, D. E. (1981). An interactive activation model of context effects in letter perception: Part 1. An account of basic findings. Psychological Review, 88(5), 375-407.

Mechelli, A., Price, C. J., Friston, K. J., \& Ishai, A. (2004). Where bottom-up meets top-down: neuronal interactions during perception and imagery. Cerebral Cortex, 14(11), 1256-1265.
Miller, J., Patterson, T., \& Ulrich, R. (1998). Jackknife-based method for measuring LRP onset latency differences. Psychophysiology, 35(1), 99-115.

Misra, M., \& Holcomb, P. J. (2003). Event-related potential indices of masked repetition priming. Psychophysiology, 40(1), 115-130.

Morton, J. (1969). Interaction of information in word recognition. Psychological Review, 76(2), 165-178.

Mumford, D. (1992). On the computational architecture of the neocortex: II. The role of cortico-cortical loops. Biological Cybernetics, 66(3), 241-251.

Murray, W. S., \& Forster, K. I. (2004). Serial mechanisms in lexical access: the rank hypothesis. Psychological Review, 111(3), 721-756.

Nieuwland, M. S., \& Kuperberg, G. R. (2008). When the truth is not too hard to handle: an event-related potential study on the pragmatics of negation. Psychological Science, 19(12), 1213-1218.

Nieuwland, M. S., \& Van Berkum, J. J. A. (2006). Individual differences and contextual bias in pronoun resolution: evidence from ERPs. Brain Research, $1118,155-167$.

O'Connor, D. H., Fukui, M. M., Pinsk, M. A., \& Kastner, S. (2002). Attention modulates responses in the human lateral geniculate nucleus. Nature Neuroscience, 5(11), 1203-1209

Onifer, W., \& Swinney, D. A. (1981). Accessing lexical ambiguities during sentence comprehension: effects of frequency of meaning and contextual bias. Memory and Cognition, 9(3), 225-236.

Otten, M., Nieuwland, M. S., \& van Berkum, J. J. A. (2007). Great expectations: specific lexical anticipation influences the processing of spoken language. $B M C$ Neuroscience, 8

Otten, M., \& Van Berkum, J. J. A. (2008). Discourse-based word anticipation during language processing: prediction or priming? Discourse Processes, 45(6) 464-496

Penolazzi, B., Hauk, O., \& Pulvermüller, F. (2007). Early semantic context integration and lexical access as revealed by event-related brain potentials. Biological Psychology, 74(3), 374-388.

Pickering, M. J., \& Garrod, S. (2007). Do people use language production to make predictions during comprehension? Trends in Cognitive Sciences, 11(3) $105-110$.

Pulvermüller, F., Shtyrov, Y., \& Hauk, O. (2009). Understanding in an instant: neurophysiological evidence for mechanistic language circuits in the brain. Brain and Language, 110(2), 81-94.

Rayner, K. (1998). Eye movements in reading and information processing: 20 years of research. Psychological Bulletin, 124(3), 372-422.

Rayner, K. (2009). Eye movements and attention in reading, scene perception, and visual search. Quarterly Journal of Experimental Psychology, 62(8), 1457-1506.

Rayner, K., Ashby, J., Pollatsek, A., \& Reichle, E. D. (2004). The effects of frequency and predictability on eye fixations in reading: implications for the $\mathrm{E}-\mathrm{Z}$ reader model. Journal of Experimental Psychology: Human Perception and Performance, $30(4), 720-732$

Rayner, K., Binder, K. S., Ashby, J., \& Pollatsek, A. (2001). Eye movement control in reading: word predictability has little influence on initial landing positions in words. Vision Research, 41(7), 943-954.

Rayner, K., \& Clifton, C. (2009). Language processing in reading and speech perception is fast and incremental: implications for event-related potential research. Biological Psychology, 80(1), 4-9.

Rayner, K., Pollatsek, A., Ashby, J., \& Clifton, C. (2012). The Psychology of Reading. New York: Psychology Press.

Rayner, K., \& Well, A. D. (1996). Effects of contextual constraint on eye movements in reading: a further examination. Psychonomic Bulletin and Review, 3(4), 504-509

Reichle, E. D., Pollatsek, A., Fisher, D. L., \& Rayner, K. (1998). Toward a model of eye movement control in reading. Psychological Review, 105(1), 125-157.

Robichon, F., Besson, M., \& Habib, M. (2002). An electrophysiological study of dyslexic and control adults in a sentence reading task. Biological Psychology, 59(1), 29-53.

Rossell, S. L., Price, C. J., \& Nobre, A. C. (2003). The anatomy and time course of semantic priming investigated by fMRI and ERPs. Neuropsychologia, 41(5) 550-564

Rubenstein, H., Garfield, L., \& Millikan, J. A. (1970). Homographic entries in the internal lexicon. Journal of Verbal Learning and Verbal Behavior, 9(5), 487-494.

Rugg, M. D. (1990). Event-related brain potentials dissociate repetition effects of high- and low-frequency words. Memory and Cognition, 18(4), 367-379.

Rumelhart, D. E., \& McClelland, J. L. (1982). An interactive activation model of context effects in letter perception: Part 2. The contextual enhancement effect and some tests and extensions of the model. Psychological Review, 89(1) $60-94$.

Schuberth, R. E., \& Eimas, P. D. (1977). Effects of context on classification of words and nonwords. Journal of Experimental Psychology: Human Perception and Performance, 3(1), 27-36.

Schvaneveldt, R. W., Meyer, D. E., \& Becker, C. A. (1976). Lexical ambiguity, semantic context, and visual word recognition. Journal of Experimental Psychology: Human Perception and Performance, 2(2), 243-256.

Sereno, S. C., Brewer, C. C., \& O'Donnell, P. J. (2003). Context effects in word recognition: evidence for early interactive processing. Psychological Science, 14(4), 328-333.

Sereno, S. C., Rayner, K., \& Posner, M. I. (1998). Establishing a time-line of word recognition: evidence from eye movements and event-related potentials. Neuroreport, 9(10), 2195-2200. 
Simola, J., Holmqvist, K., \& Lindgren, M. (2009). Right visual field advantage in parafoveal processing: evidence from eye-fixation-related potentials. Brain and Language, 111(2), 101-113.

Simpson, G. B. (1981). Meaning dominance and semantic context in the processing of lexical ambiguity. Journal of Verbal Learning and Verbal Behavior, 20(1), $120-136$.

Simpson, G. B. (1994). Context and the processing of ambiguous words. In: M. Gernsbacher (Ed.), Handbook of Psycholinguistics (pp. 359-374). San Diego: Academic Press.

Somers, D. C., Dale, A. M., Seiffert, A. E., \& Tootell, R. B. H. (1999). Functional MRI reveals spatially specific attentional modulation in human primary visua cortex. Proceedings of the National Academy of Sciences of the United States of America, 96(4), 1663-1668.

Stanovich, K. E., \& West, R. F. (1983). On priming by a sentence context. Journal of Experimental Psychology: General, 112(1), 1-36.

Swaab, T. Y., Camblin, C. C., \& Gordon, P. C. (2004). Electrophysiological evidence for reversed lexical repetition effects in language processing. Journal of Cognitive Neuroscience, 16(5), 715-726.

Swinney, D. A. (1979). Lexical access during sentence comprehension: (Re)consideration of context effects. Journal of Verbal Learning and Verbal Behavior, 18(6), 645-659.

Tabossi, P. (1988). Effects of context on the immediate interpretation of unambiguous nouns. Journal of Experimental Psychology: Learning, Memory, and Cognition, 14(1), 153-162.

Taft, M. (1979). Recognition of affixed words and the word frequency effect Memory and Cognition, 7(4), 263-272.

Ullman, S. (1995). Sequence seeking and counter streams: a computational model for bidirectional information flow in the visual cortex. Cerebral Cortex, 5(1), 1-11.

Ulrich, R., \& Miller, J. (2001). Using the jackknife-based scoring method for measuring LRP onset effects in factorial designs. Psychophysiology, 38(5), 816-827.
Van Berkum, J. J. A. (2004). Sentence comprehension in a wider discourse: can we use ERPs to keep track of things?. In: M. Carreiras, \& C. C. Jr (Eds.), The On-line Study of Sentence Comprehension: Eyetracking, ERPs and Beyond (pp. 229-270). New York: Psychology Press.

Van Berkum, J J. A, Brown, C. M. Zwitserlood, P., Kooijman, V. \& Hagoort, P. (2005). Anticipating upcoming words in discourse: evidence from ERPs and reading times. Journal of Experimental Psychology: Learning, Memory, and Cognition, 31(3), 443-467.

Van Petten, C. (1995). Words and sentences: event-related brain potential measures. Psychophysiology, 32(6), 511-525.

Van Petten, C., \& Kutas, M. (1990). Interactions between sentence context and word frequency in event-related brain potentials. Memory and Cognition, 18(4), 380-393.

Van Petten, C., \& Luka, B. J. (2012). Prediction during language comprehension: benefits, costs, and ERP components. International Journal of Psychophysiology, 83(2), 176-190.

West, R. F., \& Stanovich, K. E. (1982). Source of inhibition in experiments on the effect of sentence context on word recognition. Journal of Experimental Psychology: Learning, Memory, and Cognition, 8(5), 385-399.

Wicha, N. Y., Bates, E. A., Moreno, E. M., \& Kutas, M. (2003). Potato not pope: human brain potentials to gender expectation and agreement in Spanish spoken sentences. Neuroscience Letters, 346(3), 165-168.

Wicha, N. Y., Moreno, E. M., \& Kutas, M. (2004). Anticipating words and their gender: an event-related brain potential study of semantic integration, gender expectancy, and gender agreement in Spanish sentence reading. Journal of Cognitive Neuroscience, 16(7), 1272-1288.

Williams, M. A., Baker, C. I., Op de Beeck, H. P., Mok Shim, W., Dang, S., Triantafyllou, C., et al. (2008). Feedback of visual object information to foveal retinotopic cortex. Nature Neuroscience, 11(12), 1439-1445. 